\title{
Early transcriptional changes in the reef-building coral Acropora aspera in response to thermal and nutrient stress
}

Nedeljka Rosic $1^{*}$, Paulina Kaniewska ${ }^{1,2}$, Chon-Kit Kenneth Chan ${ }^{3}$, Edmund Yew Siang Ling ${ }^{4}$, David Edwards ${ }^{3,5,6}$, Sophie Dove ${ }^{1,7}$ and Ove Hoegh-Guldberg ${ }^{1,7}$

\begin{abstract}
Background: Changes to the environment as a result of human activities can result in a range of impacts on reef building corals that include coral bleaching (reduced concentrations of algal symbionts), decreased coral growth and calcification, and increased incidence of diseases and mortality. Understanding how elevated temperatures and nutrient concentration affect early transcriptional changes in corals and their algal endosymbionts is critically important for evaluating the responses of coral reefs to global changes happening in the environment. Here, we investigated the expression of genes in colonies of the reef-building coral Acropora aspera exposed to short-term sub-lethal levels of thermal $\left(+6^{\circ} \mathrm{C}\right)$ and nutrient stress (ammonium-enrichment: $\left.20 \mu \mathrm{M}\right)$.

Results: The RNA-Seq data provided hundreds of differentially expressed genes (DEGS) corresponding to various stress regimes, with 115 up- and 78 down-regulated genes common to all stress regimes. A list of DEGs included up-regulated coral genes like cytochrome c oxidase and NADH-ubiquinone oxidoreductase and up-regulated photosynthetic genes of algal origin, whereas coral GFP-like fluorescent chromoprotein and sodium/potassium-transporting ATPase showed reduced transcript levels. Taxonomic analyses of the coral holobiont disclosed the dominant presence of transcripts from coral ( 70\%) and Symbiodinium ( 10-12\%), as well as 15-20\% of unknown sequences which lacked sequence identity to known genes. Gene ontology analyses revealed enriched pathways, which led to changes in the dynamics of protein networks affecting growth, cellular processes, and energy requirement.
\end{abstract}

Conclusions: In corals with preserved symbiont physiological performance (based on FV/Fm, photo-pigment and symbiont density), transcriptomic changes and DEGs provided important insight into early stages of the stress response in the coral holobiont. Although there were no signs of coral bleaching after exposure to short-term thermal and nutrient stress conditions, we managed to detect oxidative stress and apoptotic changes on a molecular level and provide a list of prospective stress biomarkers for both partners in symbiosis. Consequently, our findings are important for understanding and anticipating impacts of anthropogenic global climate change on coral reefs.

\section{Background}

Reef-building corals form obligate mutualistic symbiosis with unicellular photosynthetic dinoflagellates (genus Symbiodinium), which is based on the exchange of inorganic and photosynthetic compounds between the host and endosymbiotic algae [1-3]. Elevated sea surface temperatures (SSTs) have been recognized as

\footnotetext{
* Correspondence: n.rosic@uq.edu.au

${ }^{1}$ School of Biological Sciences, The University of Queensland, Brisbane Qld 4072, Australia

Full list of author information is available at the end of the article
}

the most important environmental variable leading to coral bleaching $[4,5]$, where SSTs of merely $1^{\circ} \mathrm{C}$ above the long-term summer maxima can result in mass bleaching events [4]. The future trajectory according to the Intergovernmental Panel on Climate Change (IPCC 2007), based on continuing increase in $\mathrm{CO}_{2}$ emission, unfortunately predicts a further increase in temperature during the $21^{\text {st }}$ century [6].

Another important anthropogenic stress factor is pollution of coastal waters. Reef corals can be negatively affected by nutrient enrichment such as dissolved Nitrogen $(\mathrm{N})$ that may result in increased incidence of 
coral bleaching, leading to a further reduction in the abundance and distribution of reef-building corals [7-10]. In other cases, elevated amounts of $\mathrm{N}$ have been reported to positively impact coral growth and symbiont density $[11,12]$ and have been found to increase the percentage of algae released from host [13].

A number of studies have explored the effects of environmental stress on the physiological performance of the coral host, its associated microorganisms and the effect on changes in the gene expression levels [10,14-22]. Novel genomic tools such as microarray analyses have brought an overview on the instant changes in the expression levels of hundreds, thousands or even more genes and at the same time, providing more information about the organism's response to changes in the environment $[14,17,23-26]$. Next generation sequencing technologies provide a more comprehensive picture of changes in RNA expression profiles under different experimental conditions [27]. Only a few studies have applied the RNA-Seq approach to explore the effect of ocean acidification on coral calcification [22], the effect of heat and settlement inducers on the gene expression profiles of aposymbiotic larvae [28] and the molecular pathways involved in coral resilience to thermal stress [29]. Most recently, RNA-Seq revealed molecular pathways involved in heatinduced stress response of the coral Porites astreoides from thermally distinct reef habitats [30].

Here, we address the existing knowledge gap regarding the detection of early molecular changes after exposure to environmental stress at the level of the coral holobiont, which includes both coral and associated endosymbionts. On the global scale, thermaldriven stress and nutrient enrichment can negatively affect the well-being of corals, although the impacts may vary depending on stress level and coral species examined $[8,31,32]$. It is, therefore, important to describe the mechanisms and early warning signs at the molecular level before physiological changes leading to coral bleaching and potentially coral mortality are irreversible. In the present study, we exposed the reef-building coral Acropora aspera to 3-day thermal and nutrient (ammonium-enrichment) stress regimes and applied the RNA-Seq method (Illumina technology) to identify changes in the gene expression patterns between control and stress conditions. As part of the study, we identified genes/pathways in the coral holobiont involved in the response to shortterm thermal and nutrient stress. Our results provide new insights into the transcriptional profiles of the coral holobiont and transcriptional regulation prior to bleaching. In addition, we identified a range of potential gene stress biomarkers that could be used for the detection of sub-lethal stress in reef-building corals.

\section{Results}

Physiological performance

Photosynthetic efficiency of Symbiodinium in A. aspera, from pulse amplitude modulated fluorometry (PAM), revealed an overall increase in the maximum quantum yield $(F \mathrm{v} / F \mathrm{~m})$ of photosystem II (PSII) at midday across all treatments (Figure 1A). Specifically, $F \mathrm{v} / F \mathrm{~m}$ at midday showed fluctuation as a consequence of both treatment (Kruskal-Wallis, $\mathrm{H}_{2,45}=20.57, p<0.001$ ) and also day (Kruskal-Wallis, $\mathrm{H}_{2}, 45=13.67, p=0.001$ ), where the

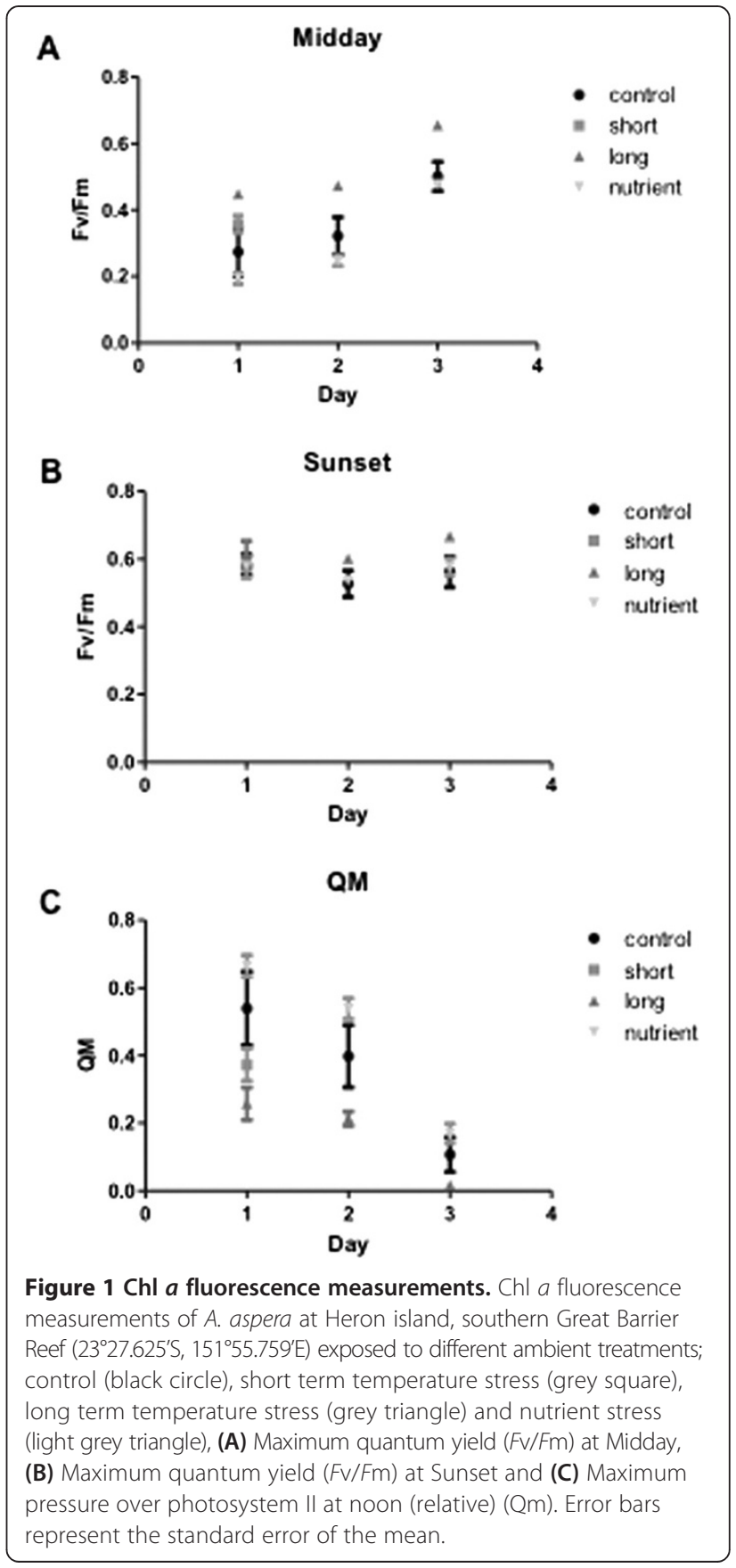


long thermal stress resulted in higher values of $\mathrm{Fv} / F \mathrm{~m}$ compared to control (18\% increase after 1-day, $46 \%$ after 2 -day and 30\% after 3-day period) and nutrient treatments (2.2-fold higher on day 1, 95\% on day 2 and $34 \%$ on day 3 ). At sunset $F \mathrm{v} / F \mathrm{~m}$ varied with experimental treatment (Kruskal-Wallis, $\mathrm{H}_{2,45}=11.16, p=0.005$ ), with $\sim 15 \%$ higher value in the long-term temperature stress treatment than in the control and nutrient treatments, and did not vary among days (Kruskal-Wallis, $\mathrm{H}_{2,45}=2.99, p=0.224$ ).

Maximum excitation pressure over PSII (Qm) varied with experimental treatment (Kruskal-Wallis, $\mathrm{H}_{2,45}=$ 11.16, $p=0.038$ ) and day (Kruskal-Wallis, $\mathrm{H}_{2,45}=22.73$, $p<0.001)$, and showed overall decreased with time (Figure 1C). Corals exposed to nutrient treatment had a 2.6-fold higher Qm than the long-term temperature stress treatment on day $1,35 \%$ and a 2.5 -fold higher Qm than control and long term temperature stress on day 2 and a 2-fold higher Qm than the long term temperature stress treatment on day 3. Coral branches in the short-term temperature stress treatment did not change their photosynthetic activity compared to control branches at midday ( $t$-test, $\left.\mathrm{t}_{1,8}=5.08, p=0.144\right)$ and sunset ( $t$-test, $\mathrm{t}_{1,8}=1.28, p=0.814$ ) and there was no change in $\mathrm{Qm}\left(t\right.$-test, $\left.\mathrm{t}_{1,8}=3014, p=0.292\right)$ (Figure 1 ).

We monitored population density of Symbiodinium and the concentration of chlorophyll a under thermal and nutrient stress conditions as indicators of stress and coral bleaching. There was no difference in the algal cell density between treatment and control (Additional file 1A, $t$-test; $p>0.05$ ). Also, chlorophyll a concentration (per surface area) did not differ between corals exposed to elevated temperatures and nutrient enrichment conditions $(p>0.05$; Additional file 1B).

\section{Analyses of differentially expressed genes}

We compared gene expression profiles between control and treatment conditions that included thermal and nutrient stress using RNA-Seq technology. Illumina massivelyparallel sequencing produced between 14-27 million reads (99 bp) per treatment. The analysis was performed using the Differential Kmer Analysis Pipeline (DiffKAP) method which progressively analyse the sequence data from $k$-mer to read and finally to gene level. The pipeline identified over a million differentially expressed reads (DERs) per treatment. Comparison of these DERs with the high quality annotated and non-redundant protein database, Swiss-Prot, resulted in successfully annotating around $10 \%$ of DERs (The DiffKAP run summaries containing all intermediate results are shown in Additional file 2: Table S1; Additional file 3: Table S2; Additional file 4: Table S3). After the standard DiffKAP analysis, two extra filtering steps on the results were applied for ensuring that other species in these complex metetranscriptome samples were not introducing false positive
DEGs. The extra filtering was performed using the DiffKAP gene-centric summary file, which contains all annotated genes with their corresponding number of up- and down-regulated DERs in different columns. Annotated genes with fewer supporting DERs are possibly from other species within the coral holobiont, which are less abundant than coral and Symbiodinium. Using only annotated genes that contained 10 or more DERs as a cut-off value to obtain confident differentially expressed genes (DEGs) - corresponded to 14.75 $21.61 \%$ of all annotated genes - we identified: 3550 DEGs in short thermal stress exposure (STE) vs. control (CTRL); 1875 DEGs for long thermal stress exposure (LTE) vs. CTRL; and 1956 DEGs in Nutrient stress (N) vs. CTRL. Inconsistent expression profiles in particular genes may be due to various reasons, such as different expression levels of isoforms of a gene and less confident blast hits of short sequences. To prevent false positive DEGs we did additional filtering for DEGs with consistent expression profiles (containing all DERs annotated to the same DEGs with the same up- or down-regulation expression patterns under a specific experimental regime, i.e. either the up or down column in the DiffKAP genecentric summary file will need to be zero). This reduced the list of DEGs by 50\%: 1785 DEGs in STE vs. CTRL; 773 DEGs for LTE vs. CTRL; and 1111 DEGs in N vs. CTRL. The overall ratios of up- and down-regulated DEGs between treatments are presented in Figure 2 and include the numbers of DEGs unique to specific treatments and also DEGs shared between treatments. A complete list of 115 up- and 78 down-regulated DEGs commonly expressed in all stress regimes is provided in Additional file 5: Table S4 and Additional file 6: Table S5, while some of the major DEGs shared between treatments are presented in Table 1. Overall, increased transcript abundance was noticed for some ribosomal proteins (40S 2, 3, 14 and 26; 60S 7 and 10), cytochrome c oxidase, cytochrome b, NADH-ubiquinone oxidoreductase, actin proteins, Fas apoptotic inhibitory molecule and programmed cell death protein of coral origin. Up-regulated algal DEGs included a number of photosynthetic genes of photosystem (PS) I and PSII, ATP synthase and cytochrome genes. Coral down-regulated DEGs contained different ribosomal proteins of $40 \mathrm{~S}$ (small subunits 4, 17, 23, 24, 27, 28 and 29) and $60 \mathrm{~S}$ (large subunits 13a, 14, 18a, 19, 24, 26, 27, 29, 31, $32,34,36,37,38$ and 39), tubulin alpha and beta chains, GFP-like fluorescent chromoprotein and sodium/potassium-transporting ATPase subunit alpha of coral origin. Algal down-regulated DEGs included 60S ribosomal proteins (large subunits 13, 27, 37 and 39) and algal cytochrome c oxidase.

A number of DEGs were involved in the oxidative stress response and genes encoding antioxidant enzymes discovered in this study are listed in Table 2. The STE 

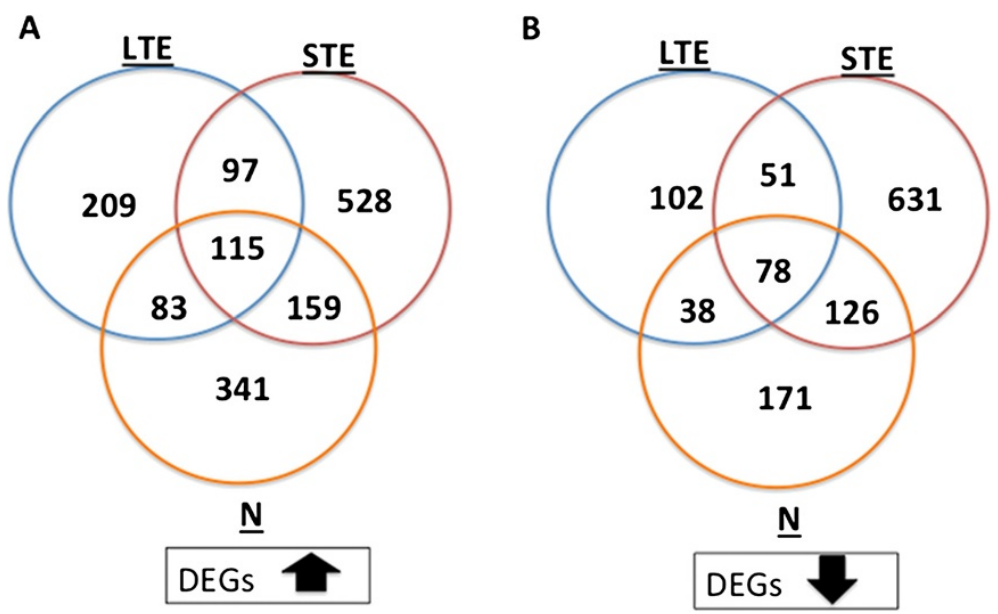

Figure 2 DEGs with up and down-regulation. Venn diagrams presenting the overlaps between DEGs with up- (A) and down-regulation (B) profiles in response to short (or 1-day) thermal stress (STE), long (or 3-day) thermal stress (LTE) and nutrient stress (N).

condition resulted in up-regulation of expression for superoxide dismutase, catalase, peroxidase, peroxiredoxin, glutathione S-transferase and thioredoxin, which are involved in the reduction of oxidative stress and capturing ROS. However, after the 3-day exposure to thermal stress (LTE), there was a down-regulation or lack of differential expression for the majority of antioxidant genes, whilst nutrient stress resulted mainly in the up-regulation of genes involved in suppressing the effects of oxidative stress.
Validation of the DiffKAP method by quantitative PCR

We validated the DiffKAP method by real-time quantitative PCR (qPCR) and compared transcript abundance of nine randomly selected DEGs, characterized by different levels of expression (based on Ratio of Medians for Treatment vs. CTRL, Additional file 7). GeneBank Accession Numbers of the targeted genes are provided in Table 1. Changes in expression of the nine coral and algal genes after a 3-day period of heat and nutrient stress were monitored by qPCR and presented in Additional file 7. Results

Table 1 Up and down-regulated genes from RNA-Seq data

\begin{tabular}{|c|c|c|c|}
\hline Origin & Biological processes & Hit description (Acc. No.) & Regulation \\
\hline \multirow{8}{*}{ Algal } & \multirow{6}{*}{ Photosynthesis } & Photosystem I P700 chlorophyll a apoprotein A1 (Q9XQV3) & \multirow{6}{*}{ UP } \\
\hline & & Photosystem I P700 chlorophyll a apoprotein A2 (P58383) & \\
\hline & & Photosystem Q(B) protein (Q9TM69) & \\
\hline & & Photosystem II D2 protein (Q9TL00) & \\
\hline & & Photosystem II CP43 chlorophyll apoprotein (Q1XDD1) & \\
\hline & & Cytochrome b6-f complex subunit 4 (Q1XDE7) & \\
\hline & \multirow{2}{*}{ Metabolism } & Cytochrome c oxidase subunit 1 (Q02766) & \multirow{2}{*}{ DOWN } \\
\hline & & ADP, ATP carrier protein (P25083) & \\
\hline \multirow{9}{*}{ Coral } & \multirow{2}{*}{ Respiratory chain, transport and electron transport } & Cytochrome b (Q8SJB6) & \multirow{5}{*}{ UP } \\
\hline & & NADH-ubiquinone oxidoreductase (Q35100) & \\
\hline & Hydrogen peroxide catabolic process & Chorion peroxidase (P82600) & \\
\hline & Ubiquitin conjugation pathway & E3 ubiquitin-protein ligase (Q9ULT8) & \\
\hline & \multirow[t]{2}{*}{ Metabolism } & Cytochrome c oxidase subunit 1 (Q35101) & \\
\hline & & Sodium/potassium-transporting ATPase subunit alpha (P06687) & \multirow{4}{*}{ DOWN } \\
\hline & \multirow[t]{2}{*}{ Transport } & Electron transfer flavoprotein-ubiquinone oxidoreductase (Q5RDD3) & \\
\hline & & V-type proton ATPase 16 kDa proteolipid subunit (P63081) & \\
\hline & Luminescence & GFP-like fluorescent chromoprotein (Q9U6Y6) & \\
\hline
\end{tabular}


Table 2 Antioxidant DEGs up- and down-regulated

\begin{tabular}{|c|c|c|c|}
\hline $\begin{array}{l}\text { Antioxidant } \\
\text { enzymes }\end{array}$ & $\begin{array}{c}\text { DEGs in STE } \\
\text { (Gene Accession No.) }\end{array}$ & $\begin{array}{c}\text { DEGs in LTE } \\
\text { (Gene Accession No.) }\end{array}$ & $\begin{array}{c}\text { DEGs in N } \\
\text { (Gene Accession No.) }\end{array}$ \\
\hline $\begin{array}{l}\text { Superoxide } \\
\text { dismutase }\end{array}$ & UP (O73872; Q8HXQ3; Q8HXQ4; P04178; Q8HXQ0) & 0 & $\begin{array}{l}\text { UP (O73872; Q8HXQ3; Q8HXQ4; } \\
\text { O46412; Q0IIW3; P80174; P80566) }\end{array}$ \\
\hline Catalase & $\begin{array}{l}\text { UP (O62839; Q9PWF7; P17336; Q9PT92; Q27487; Q9XZD5; } \\
\text { P04040; O93662; Q64405; O77229; Q216W4; P00432; P90682) }\end{array}$ & 0 & $\begin{array}{c}\text { UP (Q9PWF7; O62839; Q4AEI3; P22079; } \\
\text { Q98234) }\end{array}$ \\
\hline \multirow[t]{2}{*}{ Peroxidase } & \multirow[t]{2}{*}{ UP (P82600; Q9VEG6; P05164; P22079) } & UP (Q9VEG6; P82600) & \multirow[t]{2}{*}{ UP (P82600; Q4AEI0; Q9VEG6) } \\
\hline & & DOWN (Q4AEH2) & \\
\hline \multirow[t]{2}{*}{ Peroxiredoxin } & \multirow[t]{2}{*}{ UP (Q8T6C4; Q63716; Q9GLW9; Q9BGI1) } & \multirow{2}{*}{$\begin{array}{l}\text { DOWN(Q9V3P0; P34227; } \\
\text { O35244; Q9Z0V5) }\end{array}$} & UP (Q9Z0V5) \\
\hline & & & $\begin{array}{l}\text { DOWN (Q90384; Q9V3P0; } \\
\text { P34227; Q6DV14) }\end{array}$ \\
\hline $\begin{array}{l}\text { Glutathione S- } \\
\text { transferase }\end{array}$ & UP (Q9N1F5; Q3T100) & 0 & UP (Q3T100) \\
\hline Thioredoxin & UP (P20108; Q99MD6; Q5NVA2; Q9NNW7) & DOWN (P83877) & $\begin{array}{l}\text { DOWN (Q99MD6; O89049; } \\
\text { P91938; B9A1H3; Q86VQ6) }\end{array}$ \\
\hline
\end{tabular}

A list of antioxidant DEGs up- and down-regulated by STE, LTE and N treatments including their Gene accession Numbers in the reef building coral A. aspera. Only DEGs containing 10 or more DERs are included.

revealed the positive correlation in gene expression changes (up- or down-regulation) identified by both methods, qPCR and RNA-Seq, and verified the appropriateness of the $k$-mer approach as implemented in the DiffKAP method.

In order to explore potential stress biomarkers, we also evaluated the level of transcript abundance in several candidates proposed by the DiffKAP analyses (Table 3) and from previous studies [15]. Coral and dinoflagellate molecular chaperones, Heat Shock Proteins (HSPs), showed increased levels of expression, but significant change was observed only for algal Hsp 90 in STE and N, but not LTE (Figure 3). Up-regulation of Symbiodinium Hsp90 was significant after 1 day of exposure to elevated temperatures (1.6-fold; $t$-test: $\left.\mathrm{t}_{4}=-3.98, p=0.016\right)$ and ammonium enrichment conditions (1.4-fold; $t$-test: $\mathrm{t}_{4}=-4.90, p=0.008$ ). Significant down-regulation was observed for coral green fluorescent protein (GFP)-like fluorescent chromoprotein under nutrient stress conditions (0.24-fold; $\mathrm{t}_{4}=-3.15 p=$ 0.034). During 1-day thermal stress increased expression was noted for algal cytochrome c oxidase subunit 1 (2.4fold; $t$-test: $\left.\mathrm{t}_{4}=-3.15 p=0.034\right)$ and $N A D H$-ubiquinone oxidoreductase (2.2-fold; $t$-test: $\left.t_{4}=-2.91 p=0.034\right)$. The changes in targeted algal genes were significant under nutrient enriched conditions showing up-regulation for ribulose bisphosphate carboxylase for a 2.1-fold increase ( $t$-test: $\left.t_{4}=-3.50, p=0.024\right)$ and carotenochlorophyll a-c-binding protein for a 3.2 -fold rise $\left(t\right.$-test: $\left.\mathrm{t}_{4}=-3.34, p=0.028\right)$.

\section{Functional profile and gene ontology (GO) enrichment analyses}

In coral samples exposed to thermal and nutrient stress conditions a number of significantly enriched molecular pathways were detected (Table 4). Examples of enriched pathways after 1-day thermal stress included: ribosome, proteasome, ubiquitin-mediated proteolysis, calcium signalling pathway, citrate cycle also known as TCA (tricarboxylic acid) or Krebs cycle; whilst thermal stress lasting for a 3 -day period resulted in the enrichment of the

Table 3 qPCR analyses of DEGs

\begin{tabular}{|c|c|c|c|c|}
\hline $\begin{array}{l}\text { Symbol (C-Coral } \\
\text { or A-algae) }\end{array}$ & $\begin{array}{c}\text { GenBank accession } \\
\text { number }\end{array}$ & Annotation & $\begin{array}{l}\text { Species with the best } \\
\text { BLAST (GenBanAcc) }\end{array}$ & E-value \\
\hline Hsp90 (C) & JT002485 & Heat shock protein HSP 90-alpha & Rattus norvegicus (P82995) & 4.00E-11 \\
\hline GFP (C) & EZ013774 & GFP-like fluorescent chromoprotein & Anemonia majano (Q9U6Y6) & 3.00E-09 \\
\hline$N A D H(C)$ & JT002895 & NADH-ubiquinone oxidoreductase & Metridium senile(O47498) & 2.00E-10 \\
\hline $\operatorname{Tyr}(C)$ & JT013311 & Tyrosyl-tRNA synthetase & Danio rerio (Q6TGS6) & 2.00E-09 \\
\hline Cyt_c (C) & JT015689 & Cytochrome c oxidase subunit 1 & Metridium senile (Q35101) & $2.00 \mathrm{E}-11$ \\
\hline Rubisco (A) & GAFO01026698 & Ribulose bisphosphate carboxylase & Symbiodinium sp. (Q41406) & $6.00 \mathrm{E}-13$ \\
\hline Peridinin (A) & JN602625 & Peridinin-chlorophyll a-binding protein & Symbiodinium sp. (P51874) & $6.00 \mathrm{E}-11$ \\
\hline Car_Chl (A) & FN646420 & Caroteno-chlorophyll a-c-binding protein & Amphidinium carterae (P55738) & 2.00E-08 \\
\hline
\end{tabular}

GenBank accession number, the best BLASTx (against Swiss-Prot database) and functions of selected highly abundant DEGs based on $k$-mer analyses used for qPCR analyses. 


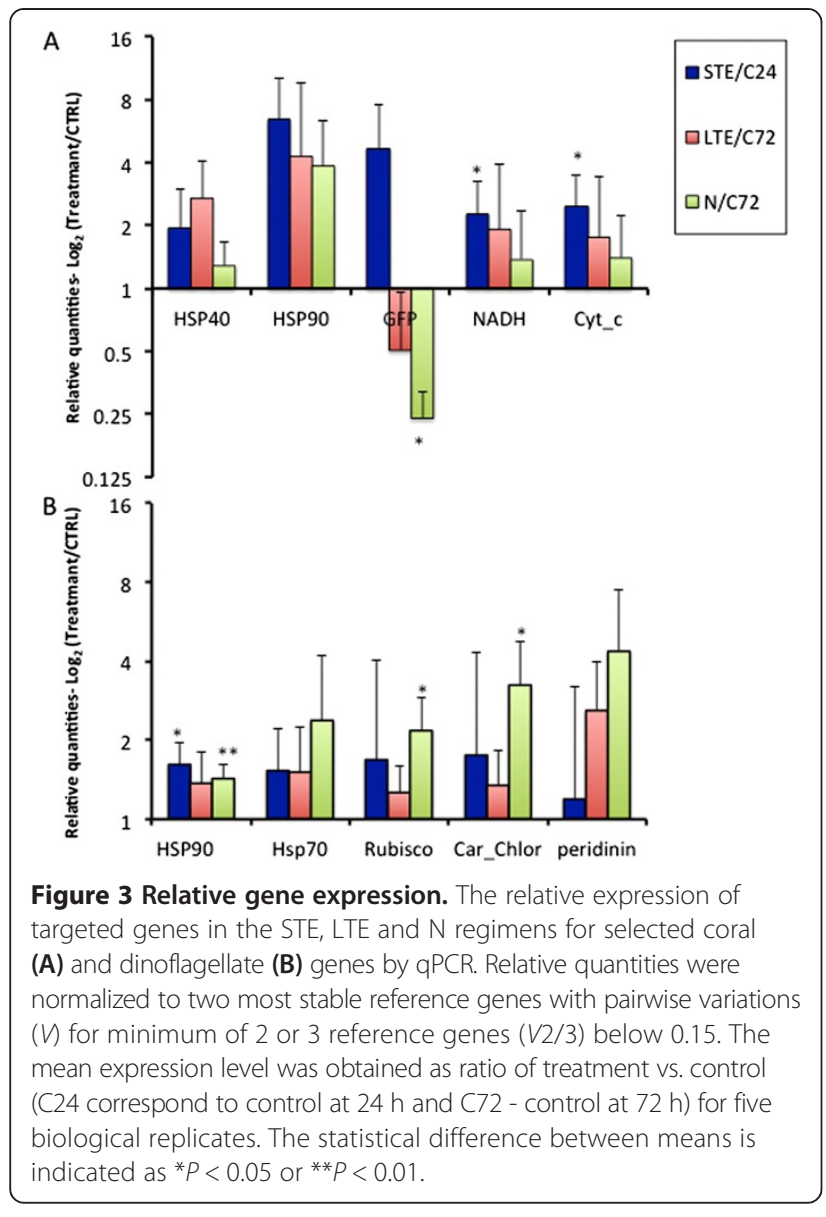

following pathways (Table 4): ribosome, valine, leucine and isoleucine degradation, insulin signalling pathway, ubiquitin mediated proteolysis and spliceosome. Nutrient stress resulted in the enrichment of ten pathways, with two pathways, ribosome and ubiquitin mediated proteolysis, commonly enhanced by all stress regimens.

Examples of enriched GO categories after 1-day thermal stress conditions (corrected $P$-value by Benjamini $P<0.001$ ) included 27 biological process (BP) categories, 13 molecular function (MF) and 9 cellular component (CC) categories. The 3-day thermal stress caused the enrichment of $16 \mathrm{BP}$ categories, $7 \mathrm{MF}$ and $8 \mathrm{CC}$ categories. After exposure to a nutrient stress regime, we observed enrichment in $46 \mathrm{BP}$ categories, $18 \mathrm{MF}$ and $19 \mathrm{CC}$ categories. BP-enriched categories included: photosynthesis, metabolic processes, cell cycle and development, transport (after 3-day stress), protein degradation, and cell death (under nutrient stress) as presented in Figure 4. Top 10 enriched BP, MF and CC categories based on the fold enrichment are presented in Additional file 8: Table S6; Additional file 9: Table S7; Additional file 10: Table S8.

\section{Taxonomic analyses}

Taxonomic composition of the coral holobiont samples was obtained after aligning millions of short sequence reads to publicly available sequence databases and the Symbiodinium de novo transcriptome assemblies generated by our group [33]. The total number and percentage of reads aligning to the various databases used in this study are provided in the Additional file 11: Table S9 and Additional file 12: Table S10. The taxonomic analyses revealed dominant presence of coral transcripts (up to $72 \%$ of sequences) under both control and stress conditions (Figure 5). The second most dominant group with attribution, comprising $\sim 10-12 \%$ of transcripts, corresponded to the Symbiodinium databases and 1-2\% of transcripts had hits to sequences belonging to environmental samples and various organisms such as bacteria, viruses, fungi, plants and algae, invertebrates, and even humans. The remaining $15 \%$ to $22 \%$ of short reads lacked a significant match in the databases (Figure 5). Exposure to stress resulted in overall increased abundance of bacterial and viral transcripts up to $~ 10$-fold compared to control conditions, despite our sequencing being limited to poly-A-containing mRNA molecules (Additional file 11: Table S9 and Additional file 12: Table S10).

\section{Discussion}

Molecular and physiological responses represent the first line of defense in reducing potentially harmful effects of unfavorable conditions in the environment. Our understanding of the underlying mechanisms of the coral holobiont stress response, however, is still limited. Gene expression studies offer a powerful approach for better understanding the complexity of how organisms respond to changes in their environment. Coral communities are facing increasing thermal stress, with mass coral bleaching often triggered by relatively small temperature increases over long-term summer maxima [4]. On the Great Barrier Reef, natural bleaching conditions were described after a 5-day period of temperatures between $31^{\circ} \mathrm{C}$ and $32^{\circ} \mathrm{C}$ [5,34], although coral susceptibility to thermal induced bleaching may vary among reefs with different historical thermal backgrounds [35-38]. Studies have shown that both coral host and Symbiodinium types play important roles in coral susceptibility to bleaching [39-43]. In the present study, we applied the sub-lethal level of thermal stress of $30^{\circ} \mathrm{C}\left(+6^{\circ} \mathrm{C}\right)$ that was just below the bleaching threshold, as well as ammonium enriched conditions. These conditions allowed corals to maintain healthy photosynthetic fitness based on elevated dark-adapted $F \mathrm{v} / F \mathrm{~m}$, pigment concentration and symbiont cell density (Figure 1 and Additional file 1). As we terminated the heating experiment after 1 and 3-day periods, we cannot know with the certainty that the reduction of $\mathrm{Fv} / \mathrm{Fm}$ or decrease in the number of dinoflagellates as indication of coral bleaching would occur with prolonged exposure to heat. However, it has been shown 
Table 4 Gene enrichment analyses

\begin{tabular}{|c|c|c|c|c|c|}
\hline Significant pathways & Condition & No of genes & No of KEGG genes in pathway & Fold enrichment & Corrected $P$-value \\
\hline Ribosome & \multirow{5}{*}{ STE } & 41 & 193 & 3.03 & $6.90 \mathrm{E}-09$ \\
\hline Proteasome & & 17 & 50 & 3.51 & $2.30 \mathrm{E}-03$ \\
\hline Ubiquitin mediated proteolysis & & 32 & 143 & 2.26 & $3.50 \mathrm{E}-03$ \\
\hline Calcium signaling pathway & & 35 & 193 & 2.14 & 4.70E-03 \\
\hline Citrate cycle (TCA cycle) & & 16 & 31 & 3.17 & $5.60 \mathrm{E}-03$ \\
\hline Ribosome & \multirow{5}{*}{ LTE } & 46 & 193 & 2.15 & $1.71 \mathrm{E}-05$ \\
\hline Valine, leucine and isoleucine degradation & & 25 & 53 & 2.37 & $4.28 \mathrm{E}-03$ \\
\hline Insulin signaling pathway & & 40 & 142 & 1.87 & $1.14 \mathrm{E}-02$ \\
\hline Ubiquitin mediated proteolysis & & 37 & 143 & 1.90 & 1.35E-02 \\
\hline Spliceosome & & 36 & 136 & 1.87 & $2.02 \mathrm{E}-02$ \\
\hline Ribosome & \multirow{10}{*}{$\mathbf{N}$} & 47 & 193 & 2.61 & 8.80E-09 \\
\hline Citrate cycle (TCA cycle) & & 19 & 31 & 2.91 & 5.10E-03 \\
\hline Ubiquitin mediated proteolysis & & 37 & 143 & 2.08 & $3.50 \mathrm{E}-03$ \\
\hline Valine, leucine and isoleucine degradation & & 23 & 53 & 2.45 & $3.50 \mathrm{E}-03$ \\
\hline Focal adhesion & & 40 & 204 & 1.92 & $1.20 \mathrm{E}-02$ \\
\hline Endocytosis & & 39 & 236 & 1.89 & $1.10 \mathrm{E}-02$ \\
\hline Spliceosome & & 33 & 136 & 2.01 & 1.70E-02 \\
\hline Lysosome & & 26 & 127 & 2.12 & $1.70 \mathrm{E}-02$ \\
\hline Insulin signaling pathway & & 34 & 142 & 1.89 & 4.20E-02 \\
\hline Oocyte meiosis & & 25 & 114 & 2.13 & 4.40E-02 \\
\hline
\end{tabular}

Gene enrichment analyses for coral samples exposed to thermal and nutrient stress. Significant pathways involved in short (STE), long-thermal (LTE) and nutrient (N) stress response had corrected $P$-value by Benjamini $P<0.05$.

that heat stress for a 3-4 day period often results in symbiont cell density reductions $[44,45]$. Similarly to our results, Fisher et al. reported lack of significant changes in the PSII activity for the reef-building coral A. aspera from GBR after 3 days of heat stress, followed by a drop in the
PSII activity after a 4-day period of prolonged heat stress [40].

RNA-Seq has been shown to be a reliable tool for the quantification of the gene expression levels and comparable to qPCR levels [46], whilst in this challenging

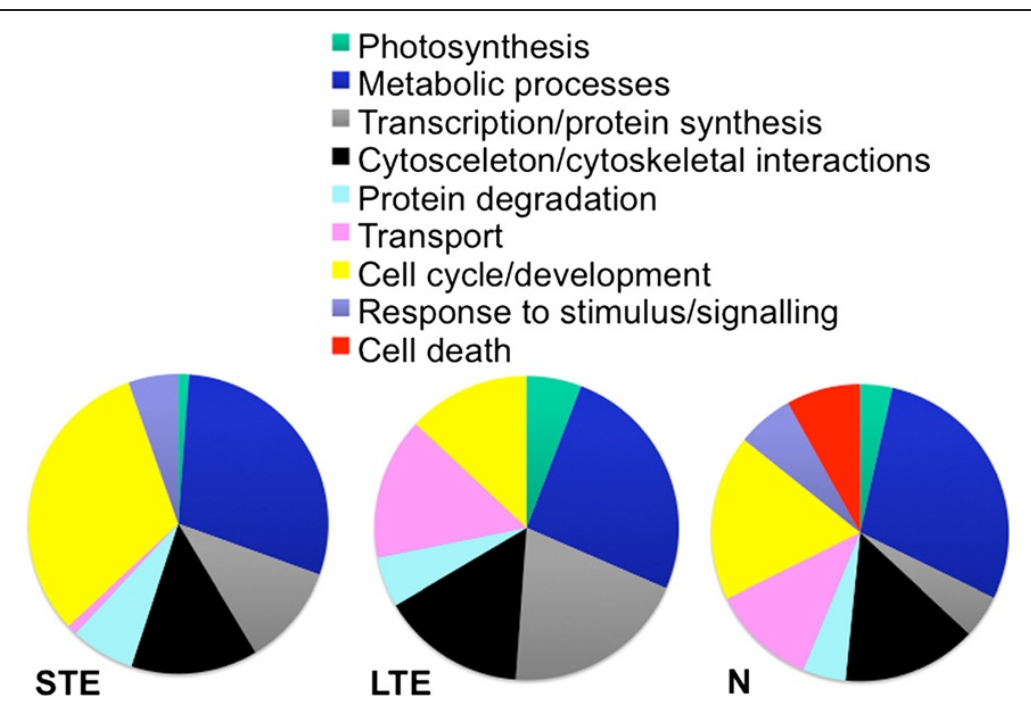

Figure 4 Biological processes enriched by stress. Biological processes enriched in the coral host A. aspera exposed to heat and nutrient stress. 
A
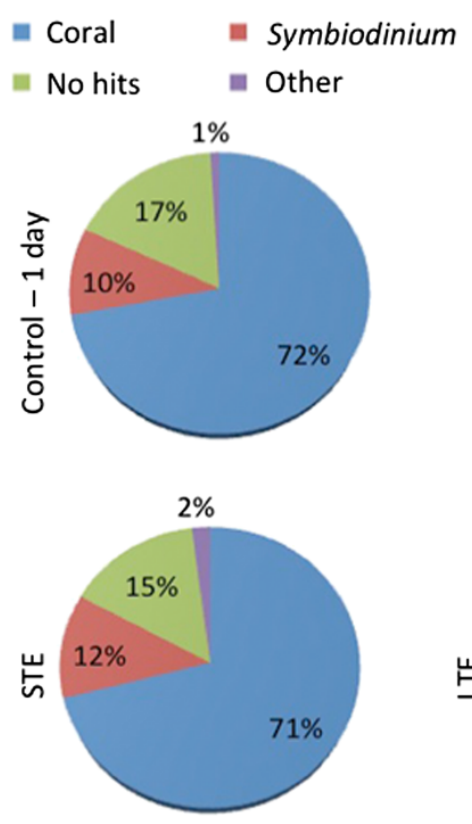

B

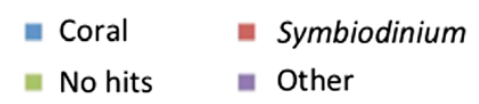

10

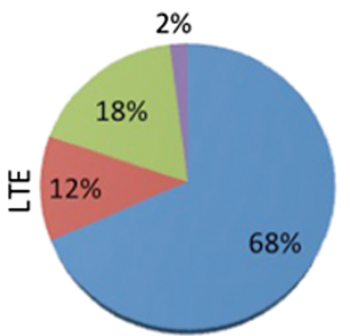

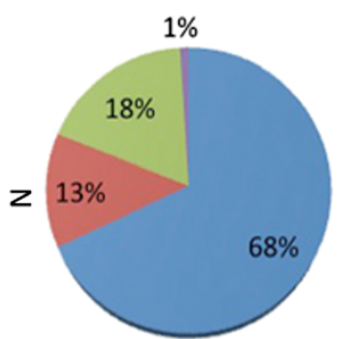

Figure 5 Taxonomic composition. Taxonomic composition within the coral holobiont obtained by aligning the millions of short reads to publicly available sequence databases, after 24-h (A) and 72-h (B) period in treatments (1-day and 3-day thermal stress and nutrient stress) and control (CTRL 24 and CTRL 72).

metatransciptome environment containing coral, dinoflagellates and other associated organisms the identification of DEGs was a difficult task. We applied a novel approach for analyzing metatranscriptomes called DiffKAP. This innovative bioinformatics method uses a pairwise comparison between Illumina read $k$-mers from control and treatment samples to estimate the changes in the level of gene expression. From DEGs revealed here, hundreds of up- and down-regulated genes of the coral holobiont have been recognized for potential use as stress biomarkers (Figure 2). These genes, differentially expressed during short-term exposure to $+6^{\circ} \mathrm{C}$-elevated temperatures and ammonium-enriched conditions, are involved in biological processes related to photosynthesis, respiration, transport and protein degradation, including genes from PSI and PSII (Table 1). During coral exposure to elevated temperatures, the photosynthetic machinery of endosymbotic dinoflagellates is susceptible to heat impairment $[45,47]$, especially the D1 protein $[48,49]$, resulting in a decline in PSII functionality $[50,51]$. Under sub-lethal levels of heat and nutrient stress, we induced transcription of a number of photosynthetic genes from PSI and PSII including expression of PSII D2 protein, confirming their sensitivity to heatinduced changes and role in the stress response (Table 1). Photosynthetic genes have been shown to play a role in minimizing photoinhibition of PSII and scavenging ROS during light-induced stress in plants [52]. In Symbiodinium cultures an initial increase in expression of photosynthetic genes ( $p s b \mathrm{~A}$ and $p s a \mathrm{~A})$ during exposure to sub-lethal heat stress of $29^{\circ} \mathrm{C}$ and $31^{\circ} \mathrm{C}$ was followed by decline after reaching the upper-thermal threshold at $32^{\circ} \mathrm{C}$ [53]. However, transcripts of organelle genes like photosynthetic genes of the dinoflagellate Lingulodinium, often have a polyuridylylated 3' residue [54], which may affect the accuracy of gene expression profiles when targeting poly-A-containing mRNA molecules using standard RNA extraction kits. The presence of a polyA tail in the transcripts of some chloroplast-encoded genes is found to be a signal of RNA degradation [55] and therefore, increase in their expression may suggest transcript degradation and destabilization [56].

We detected a trend in up-regulation of coral genes $H s p 90$ and Hsp40, although without significant changes (Figure 3 ; $t$-test, $p>0.05$ ) and an $\sim 2$-fold increase in abundance of algal HSP transcripts, which is similar to changes in Symbiodinium gene expression reported by others [15,21,57-60]. Heat shock proteins (HSPs) are molecular chaperones sensitive to temperature changes and in the coral-algal symbiosis their expression may vary depending on time and the stress regimes $[15,21,61,62]$. Previous studies have reported up-regulation of coral HSPs transcripts after short-term heat stress [17,28], but also a lack of change in expression levels of HSPs [62,63], especially after prolonged stress [28]. In other studies, down-regulation of algal $H s p 90$ expression was observed 
after more gradual increase in temperatures $\left(\sim 0.1^{\circ} \mathrm{C}\right.$ per hour) during a 5-day period [15,21]. Here, initial upregulation of algal $H s p 90$ after 1-day and lack of significant changes after a 3-day period may actually suggest a way of acclimatization to prolonged heat stress. Also in other dinoflagellates, a majority of analyzed genes showed an even transcript abundance, with a small number of genes having increased expression levels, suggesting that gene regulation was occurring at the translational or posttranslational levels [64].

Down-regulation of green fluorescent protein (GFP)like homologues was observed after the 3-day thermal and nutrient stress regimes (Figure 3). The decrease in expression of GFP-like homologues under thermal stress has been previously reported [17,65-67]. Similarly, Roth and Dehain (2013) confirmed a decrease in GFP concentration and fluorescence in the branching coral Acropora yongei, as an indicator of coral health decline before any bleaching signs could be observed [68]. Consequently, these GFP proteins should be further explored for their potential use in the development of bioluminescence chips for the evaluation of coral health.

Gene pathway enrichment analyses revealed a number of pathways involved in the coral holobiont response to changes in thermal and nutrient environmental conditions. Ribosome, ubiquitin-mediated proteolysis and valine, leucine and isoleucine degradation pathways, associated with the processes of protein synthesis and protein degradation were enriched during both thermal and nutrient stress regimes. This indicates protein perturbations and de novo protein synthesis, and overall changes in protein networks affecting the processes related to the cell cycle, immune responses, signal transduction, development and differentiation [69-72]. Protein degradation via the ubiquitin/proteasome pathway targets many short-lived regulatory proteins, such as cell cycle regulatory proteins, allowing the quick transitions between cell cycle stages [73]. We also observed a number of differentially expressed ribosomal genes of coral and microbial origin indicating shifts in the ribosomal activities (Additional file 9: Table S7 and Additional file 10: Table S8). In coral larval transcriptomes, decreased expression of ribosomal genes was observed after a 2-day [28,74] and a 5-day exposure to heat stress [28]. Our finding of calcium-signaling pathway enrichment in STE is supported by a previous study, in which intracellular calcium accumulation was induced by heat [75]. The importance of calcium signaling for dinoflagellate-cnidarian symbiosis has been recently proposed with the discovery of conserved calcium-dependent protein kinase genes in various symbiotic dinoflagellates [33].

After a 3-day period of both thermal and nutrient stress, our analyses detected enrichment of the spliceosome pathway, which demonstrates the activation of transcriptional machinery and the processes of splicing. Energy demand was also increased, which involved pathways such as the tricarboxylic acid (TCA) cycle, an essential aerobic pathway important in an organism's defence mechanism, as well as reactive oxygen species (ROS) detoxification and metabolism [76]. Others have also reported up-regulation in gene expression of TCA cycle enzymes by heat stress [21]. Insulin signaling pathways were also enriched, suggesting the role of metabolic processes such as glucose and lipid metabolism in the stress response. The insulin protein family is evolutionarily ancient [77] and insulin-related proteins have been found playing a role in signaling and growth in cnidarians [78].

During nutrient stress exposure, our results revealed the enrichment of the pathway related to ocyte meosis and the endocytosis pathway that is involved in molecule uptake. Oocyte meiosis pathway enrichment indicates gamete production was stimulated in corals. Oocyte formation was also increased by nutrient enrichment in the brooding coral Stylophora pistillata, although the final number of live planulae was reduced [79]. Ourresults show that catabolic processes are boosted by nutrient stress, as are ion transport and enzyme activities (Additional file 8: Table S6). Ammonium enrichment at the same concentration as was used in this study $(20 \mu \mathrm{M})$ resulted in increased mortality of coral larvae [80]. Here, the impact of a short period (3 days) of elevated ammonium concentrations (10-20× higher than in a typical healthy coral reef environment) was not as detrimental, although apoptotic biological processes were enriched by nutrient stress, suggesting that the tipping point leading to apoptosis had been reached (Figure 4). This is possibly due to ammonium uptake by the host and largely by symbiotic dinoflagellates [19] and also natural variation in $\mathrm{N}$ concentration, as corals are exposed to pulses of elevated amounts of $\mathrm{N}$ released by residential fishes [11]. The up-regulation in expression of the algal genes ribulose bisphosphate carboxylase and caroteno-chlorophyll a-c-binding protein under nutrient enriched conditions (Figure 3) suggests the strengthening photosynthetic capacity of coral symbionts. Similarly, feeding of the reef-building corals had a positive effect on symbiont photosynthetic capacity during thermal stress, due to boosted food provision from the coral host to algal symbionts [81].

Although physiological performance was stable (Figure 1), the signs of oxidative stress were developing at the molecular level as RNA-Seq data showed enrichment of BP related to oxidative stress and cell death (Figure 4). Dysfunction of the coral-algal symbiosis, leading to a breakdown of the symbiotic partnership often starts with the production of ROS and oxidative stress [82]. In corals, it has been proposed that antioxidants scavenge ROS produced during 
heat stress, improve photosynthetic activity and decrease bleaching events [83]. Interestingly, higher numbers of antioxidative genes have been discovered in Symbiodinium compared to related, but non-symbiotic organisms $[33,84]$, indicating the enhanced capacity to endure oxidative stress. Our results show an up-regulation in expression of antioxidant genes under STE and nutrient stress conditions (Table 2), indicating oxidative stress response, in line with the findings of DeSalvo et al. [85]. Several forms of superoxide dismutase and catalase were enriched, which is consistent with their role as the first line of defense against oxidative stress and the protection of coral-algal symbiosis from ROS [86,87]. During the LTE treatment, however, expression of superoxide dismutase and catalase was not affected, whilst peroxiredoxin and thioredoxin genes were down-regulated, suggesting possible acclimatization to elevated temperature by prolonged heat stress. Barshis et al. [29] also noticed reduced expression of antioxidant $\mathrm{Cu}-\mathrm{Zn}$ superoxide dismutase in thermo-tolerant corals compared to thermo-sensitive types. In addition, our results show that after a 3-day exposure to thermal stress, corals in fact increased $F \mathrm{v} / F \mathrm{~m}$ and consequently their photosynthetic capacity (Figure 1), further pointing to possible photo-acclimation.

Multicellular organisms like corals can be regarded as metaorganisms comprised of the host and associated prokaryotic and eukaryotic organisms [88]. In the case of the coral holobiont, this entity is presented as the partnership between corals, symbiotic dinoflagellates and other organisms including microbiota, viruses and fungi [89]. Our taxonomic analyses of the reef-building coral $A$. aspera revealed dominance of transcripts with coral $(\sim 70 \%)$ and Symbiodinium origin $(\sim 10-13 \%)$ including sequences of unknown origin ( $15-20 \%$ of total reads) with no significant matches to the sequence databases (Figure 5). This is possibly due to a large portion of sequences lacking hits to known genes and also the short sequencing reads produced by next-generation sequencing $[90,91]$. Here, additionally, we identified the presence of $1-2 \%$ of transcripts from other organisms including bacteria, archaea, fungi, viruses and even human. These results can be explained by database bias due to a high proportion of characterized sequences from some model organisms, possible gene orthologs and also the existence of poly A bacterial and viral transcripts.

Exposure to stress has been demonstrated to lead to changes in the microbiota composition and susceptibility to coral diseases [20,92], where heat stress can lead to shifts in microbial communities between healthy and bleached corals [93]. Here, stress resulted in an overall increased abundance of poly A bacterial and viral transcripts up to $\sim 10$-fold compared to control conditions. A recent proteomics study revealed a 100-fold increase in a viral replication protein in the coral Stylophora pistillata after heat stress treatment [94]. It is difficult, however, to distinguish the exact changes in the transcript abundance of specific groups of organisms due to the high proportion of unknown sequences. This will remain a recurring issue until sequencing projects, which will cover all species existing in the coral holobiont are completed.

\section{Conclusions}

Elevated sea temperatures, ocean acidification and eutrophication are recognized as major factors in destabilizing the cnidarian-dinoflagellates symbiosis and consequently coral reef ecosystems globally [4,95]. This novel study uses Illumina RNA-Seq technology to investigate the coral holobiont transcriptomic response to short-term heat and nutrient stress. We provide the comprehensive coral transcriptomic profile of the early changes happening at the molecular level before physiological and phenotypic changes can be observed. These results provide insights into the biological processes and pathways enriched by heat and ammonium augmentation such as ribosome and ubiquitin-mediated proteolysis pathways, resulting in a range of modifications in the protein networks. Our transciptomics data include the first pool of potential stress biomarkers comprised of coral and algal genes for detecting the early signs of stress in the coral holobiont. In the future, additional studies should apply "clinical trial" procedures, using different coral species and stress regimes to evaluate the biomarkers' sensitivity and potential for technological application, including the development of environmental monitoring tools such as "molecular stress kits" for corals. To conclude, this study provides new insights critical for future prediction and protection of coral reefs from global climate change.

\section{Methods}

\section{Experimental design}

Coral fragments ( $7 \mathrm{~cm}$ long) of $A$. aspera (five colonies) harbouring Symbiodinium C3 genotype [96] were collected in the winter from the reef flat at Heron Island, Great Barrier Reef, Australia $\left(23^{\circ} 25^{\prime} \mathrm{S} ; 1^{\circ} 2^{\circ} 07^{\prime} \mathrm{E}\right)$ during the low tide (June 2010). After collection, the coral fragments were immediately transferred to flow through aquaria, fixed to racks and then returned to the reef flat to acclimatise for 2 weeks. Experimental treatments were carried out in $15 \mathrm{~L}$ tanks supplied with unfiltered sea water from the reef flat with a flow rate of $0.4 \mathrm{~L}$ per min. Tanks were independently heated and water pumps (250 L per hour) were used within each tank, to provide additional flow and support even heating. The experiment started at noon and included: [1] short thermal stress exposure (STE) reaching $6-7^{\circ} \mathrm{C}$ above ambient temperature after $6 \mathrm{~h}\left(\sim 1^{\circ} \mathrm{C}\right.$ increase per $\left.\mathrm{h}, 30 \pm 1^{\circ} \mathrm{C}\right)$ 
and lasting for a 1-day period; [2] long thermal stress exposure (LTE) reaching $6^{\circ} \mathrm{C}$ above ambient temperature after $12 \mathrm{~h}\left(\sim 0.5^{\circ} \mathrm{C}\right.$ increase per $\left.\mathrm{h}, 30 \pm 1^{\circ} \mathrm{C}\right)$ and lasting for a 3-day period and finally a control group stable at $23-24 \pm 1^{\circ} \mathrm{C}$; ambient temperature over a 24 -h period (C24) and a $72 \mathrm{~h}$-period (C72). Coral branches from five different colonies (five biological replicates) were randomly distributed across flow through aquaria (three aquaria per treatment). In the case of nutrient stress condition, five coral branches $(n=5)$ were exposed to elevated ammonium concentration in a 15-L tank with recirculating system, where spiking with $1 \mathrm{M} \mathrm{NH}_{4} \mathrm{Cl}$ (once a day) reached $20 \mu \mathrm{M}$ after 3 days.

Two warming events reported on the Great Barrier Reef (GBR) that resulted in coral bleaching included temperatures between $31-32^{\circ} \mathrm{C}$ over a 5 -day period and between $25^{\circ} \mathrm{C}$ and $32^{\circ} \mathrm{C}$ over a 24-h period [5,34,97]. Here, we aimed to avoid coral bleaching and therefore we applied sub-lethal thermal stress condition with maximum of $30^{\circ} \mathrm{C}$ (that was $1-2^{\circ} \mathrm{C}$ lower than during bleaching events) for 1-day and 3-day periods. Temperatures above $30^{\circ} \mathrm{C}$ led to photosynthetic dysfunction in Symbiodinium cultures [98]. In addition, the long-thermal threshold during 1980s for the reef flat at Heron Island has been reported to be $\sim 29.5-30^{\circ} \mathrm{C}$ [99]. This concentration (ammonium-enrichment: $20 \mu \mathrm{M}$ ) represents the nutrient stress condition corresponding to 10-20 times greater ammonium concentration than found in nature $[8,100]$. For each replicate aquarium water temperature was measured every 2 min using StowAway TidbiT Loggers (Onset Computer Corporation, USA). The maximal temperature applied here was $30^{\circ} \mathrm{C}$, which is approximately $6-7^{\circ} \mathrm{C}$ higher than mean seawater temperature during the course of the experiment.

Additional details regarding experimental set up are provided in Additional file 13.

\section{$\mathrm{Chl}$ a fluorescence and maximum excitation pressure over photosystem II (Qm)}

To measure the photosynthetic activity of Symbiodinium in A. aspera exposed to the different treatments Chl $a$ fluorescence measurements were taken using a submersible fluorometer (Diving-Pam, Walz, Effeltrich, Germany). Measurements of the maximum quantum yield $(F \mathrm{v} / F \mathrm{~m})$ were taken at midday (12.00) and at sunset (17.30) for days 1,2 and 3 . Upper parts of $A$. aspera branches in experimental aquaria were selected for measurements. Maximum excitation pressure over photosystem II (Qm) was defined as: $\mathrm{Qm}=1-\left[\left(\Delta F v / F m^{\prime}\right.\right.$ at midday $) /(F v / F m$ at sunset)] following methods of Iglesias-Prieto et al. [101].

\section{Symbiodinum cell density and pigment composition}

The algal cell density within the tissue of $A$. aspera samples was done by airbrushing frozen coral fragments in $14 \mathrm{ml}$ of $0.06 \mathrm{M}$ phosphate buffer ( $\mathrm{pH}$ 6.65); followed by centrifugation of the homogenate at $4,000 \times g$ for $5 \mathrm{~min}$, re-suspension of pellet in filtered sea-water $(0.45 \mu \mathrm{m})$ and separation in aliquots. An aliquot was used for the estimation of Symbiodinium cell density using 12 randomly picked replicates in the cell counter (Sedgewick-Rafter cell). The cell counts were normalized to the surface area $\left(\mathrm{cm}^{2}\right)$ of each coral branch obtained using the melted paraffin method [13]. For pigment extraction, additional centrifugation $(4000 \times g$ for $5 \mathrm{~min})$ was applied on the aliquot used for the pigment analyses followed by the re-suspension of pellet in $1 \mathrm{ml}$ of $100 \%$ cold methanol, followed by $10 \mathrm{~min}$ sonication on ice cold water and centrifugation $(4000 \times g$ for $5 \mathrm{~min})$. Supernatant was transferred to new tube and kept on ice. Additional $1 \mathrm{ml}$ of $100 \%$ cold methanol was added to the pellet and the pigment extraction step was repeated until all pigment extract was removed from pellet (usually after $3-5$ subsequent steps). The filtered pigment extraction $(0.45 \mu \mathrm{m})$ was used for pigment separation in a Shimadzu SCL - 10 HPLC linked to a Shimadzu SPD - M10A photodiode array detector, using the column and method described by Zapata et al. (2000) with solutions A (methanol: acetonitrile: ammonium acetate, 50:25:25 v:v:v) and B (methanol: acetonitrile: acetone, 20:60:20 v:v:v). Pigments concentrations were obtained using the appropriate standards (chlorophyll a) and normalized to the surface area $\left(\mathrm{cm}^{2}\right)$.

\section{Total RNA extraction and sequencing}

Total RNA was extracted from coral branches using a small fragment $(0.5-1 \mathrm{~cm}$ long) of coral nubbins that were cut with a bone cutter and ground in liquid nitrogen. The obtained powder was put in Trizol, homogenised with a hand homogenizer (Tissue-Tearor, Biospec products, Inc.) and centrifuged for $3 \mathrm{~min}$ at 13,000 $\times g$ at $4^{\circ} \mathrm{C}$. The aqueous phase was then used for the extraction of total RNA with RNeasy kit (Invitrogen, Australia) following the manufacturer's instructions. The RNA quantity and integrity was analyzed using a NanoDrop ND-1000 spectrometer and an Agilent 2100 Bioanalyzer (RIN > 7). Equal concentrations of a high quality RNA from biological replicates $(n=5)$ were pooled together and used for sequencing using the Illumina GA II 7Sequencing System (using the Illumina ${ }^{\circ} \mathrm{TruSeq}^{\circ} \mathrm{RNA}$ Sample Preparation Kit) by Australian Genome Research Facility Ltd (AGRF) that resulted in over 6 million reads per replicate (four technical replicates) per sample.

\section{Bioinformatics analyses - analyses of differentially expressed genes}

Standard RNA-Seq analysis relies on mapping individual short sequence reads to a reference genome or transcriptome and then applying statistical tests to identify 
DEGs. However, as there is no reference transcriptome of A. aspera nor for the entire coral holobiont, it is challenging to apply the standard RNA-Seq analysis methods such as edgeR [102], DEGseq [103] or Cuffdiff [104]. De novo assembly of the RNA-Seq data requires large computing resources with high data coverage and is notoriously sensitive to sequencing error and chimeric assembled contigs [105], especially for metatranscriptome data. Therefore, we applied a DiffKAP method that allowed us to identify DEGs between two samples without using a reference.

The DiffKAP method is based on the fact that $k$-mers are the building blocks of reads which form a gene. By reducing each read to component $k$-mers and comparing the relative abundance of these sub-sequences, it overcomes statistical limitations of whole read comparative analysis. The concept of directly using $k$-mer frequency for pairwise sequence data comparison has been well explored by Nordstrom et. al. [106] to identify mutation between mutant and wild-type individuals. The $k$-mer approach is more specific than traditional hybridisation based methods of measuring the transcript abundance and it presents a greater accuracy for dinoflagellates, which consist of multi-copy gene families and pseudogenes [107].
The DiffKAP pipeline analyses a pairwise dataset by identifying differentially expressed $k$-mers (DEKs) first, then obtaining differentially expressed reads (DERs) and finally annotating the DERs to gather differentially expressed genes (DEGs). It consists of seven core processing steps, as shown in Figure 6:

Step 1: DiffKAP applies Jellyfish [108] to perform $k$-mer counting. Optimal $k$-mer size is determined by adapting the strategy of Kurt et al. [109] to identify the 'knee point' in a $k$ mer uniqueness graph. The $k$-mer size at this point balances the specificity and sensitivity of the information content.

Step 2: The abundance of each $k$-mer is normalized by dataset size.

Step 3: DEKs are determined using the following formulas:

$$
\begin{aligned}
k-\mathrm{mer}=\mathrm{DEK} \text { if } & \left(\left|O_{T 1}-O_{T 2}\right| \geq X\right) \text { and } \\
& \left(Y \times O_{T 1} \leq O_{T 2} \text { or } Y \times O_{T 2} \leq O_{T 1}\right)
\end{aligned}
$$

Where $O_{T 1}$ and $O_{T 2}$ represent the normalised $k$-mer occurrence in datasets 1 and 2 respectively, $X$ represents the minimum difference of the $k$-mer occurrence and $Y$ is the minimum fold change of $k$-mer occurrence between the two datasets required to call a $k$-mer differentially expressed.

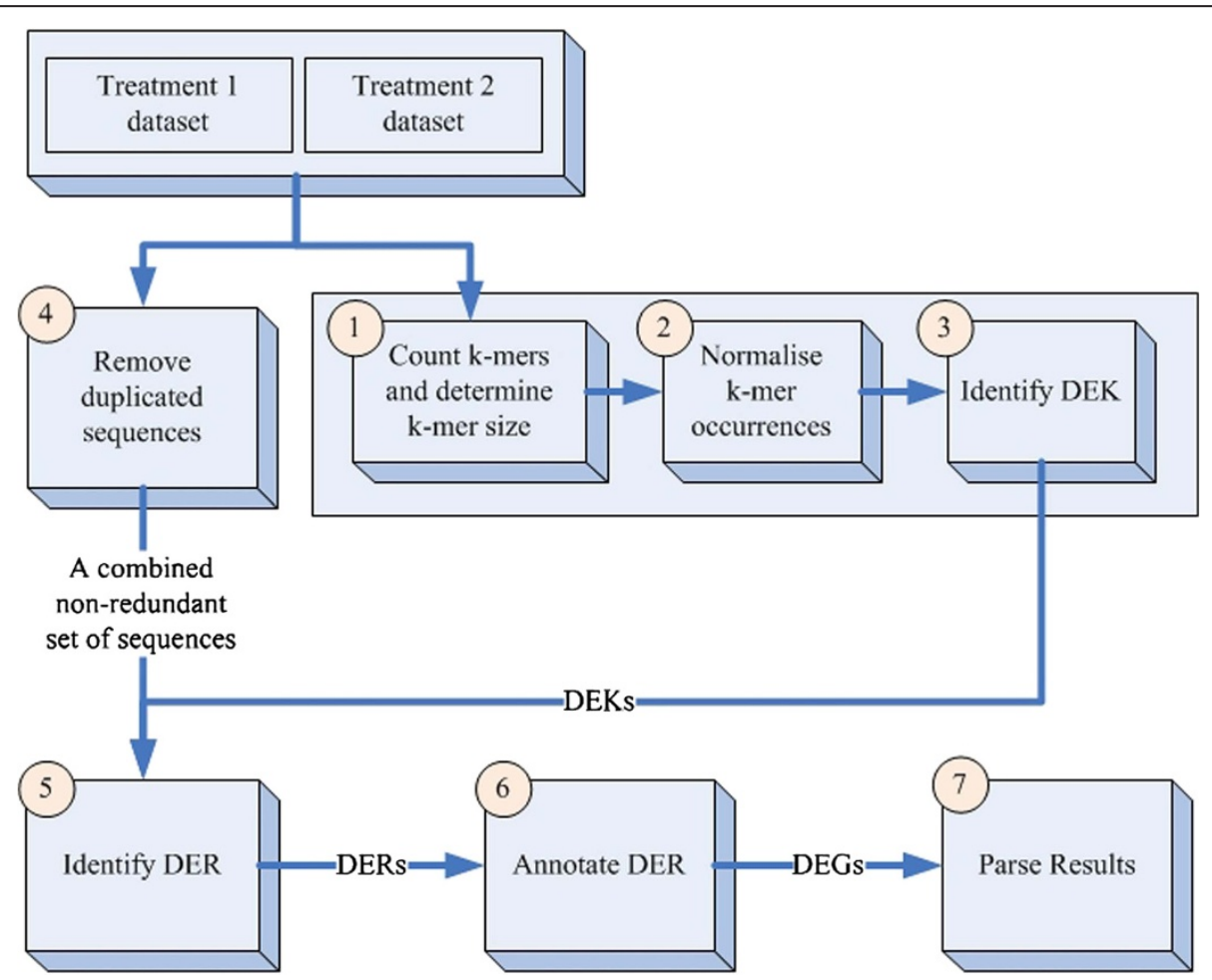

Figure 6 The DiffKAP pipeline. The schematic diagram of DiffKAP. The pipeline includes the following steps: 1- Produce a $k$-mer uniqueness plot to predict the optimum k-mer length; 2 - For each dataset, count the total number of each unique $k$-mer with the optimum length and normalise by dataset size; 3 - Identify differentially expressed $k$-mers (DEKs) by comparing abundance between datasets; 4 - Combine the original read datasets to produce a single set of unique reads; 5 - Identify differentially expressed reads (DERs) based on their composition of DEKs; 6 - The DERs are annotated to present a redundant set of differentially expressed genes (DEGs) and 7 - Finally parse the blastx output file. 
Step 4: A single set of unique reads is obtained by combining all reads in the original datasets and filtering to remove duplicated reads.

Step 5: A DER is determined by a strict criterion to minimize false positives and is defined as when all constituent $k$-mers in the read are DEKs (obtained from Step 3). The DER determination is applied to all reads in the combined non-redundant set from Step 4. For DERs, the median $k$-mer abundance is calculated for each dataset and the ratio of median $k$-mer abundance (RoM) provided as a prediction of gene expression ratio. We used a 1.5-fold change for nominated DEGs by DiffKAP. This cut-off value was chosen to include DEGs of both dinoflagellate and coral origin, as often 2 or lower fold change can be observed in Symbiodinium transcript abundance due to thermal stress exposure [15,21].

Step 6: All DERs are annotated by comparison to Swiss-Prot database [110] using a strict E-value cut off of $\leq 10^{-15}$ to form a set of DEGs.

Step 7: Parsing the blastx output file to be an informative tubular format.

The DiffKAP program is available from http://appliedbioinformatics.com.au/index.php/DiffKAP.

\section{Taxonomic composition of metatranscriptomes}

In this study we used publicly available datasets, including expressed sequence tags (ESTs), genome and transcriptome sequences. To determine the taxonomic composition of each metatranscriptome, short reads from each of the analyzed samples were aligned to sequences from Genbank databases (accessed March 2012; that included bacterial, environmental, invertebrate, plant, and viral nucleotide sequences; $A$. digitifera genome; human genome; and Symbiodinium ESTs); then additional Symbiodinium ESTs (Joint Genome Institute, University of California) and the A. millepora transcriptome [22,90]; the A. hyacinthus, A. tenuis and Porites astreoides transcriptomes (Eli Meyer, Mikhail Matz, et al. data: www.bio.utexas.edu/ research/matz_lab/); and de novo Symbiodinium transcriptomes from this lab [33]. Database alignments were carried out using the Nucleotide-Nucleotide BLAST software application (BLASTn, version 2.2.27+), specifying a word size of 14 and E-values $\leq 10^{-15}$.

\section{GO enrichment analyses}

GO enrichment analyses and pathway analyses were performed using the database for annotation, visualization and integrated discovery (DAVID) and identifications of enriched biological themes and KEGG (Kyoto Encyclopedia of Genes and Genomes) pathways [111,112]. DAVID uses the Fisher's Exact Test to ascertain statistically significant gene enrichment for a particular pathway, and significant processes were selected based on a corrected $P$-value by Benjamini [113] with a cut-off of 0.05 and even more stringent $P$-value of 0.001 . To provide information about biological functions associated with the stress response in corals we used an integrated bioinformatics approach which has been provided by GO consortium [114] and DAVID bioinformatics resources [90]. We used the GO FAT database that has been developed as a part of annotation tool within the DAVID suite [115]. This database presents a subset containing more specific GO terms and reducing redundancy in big GO datasets prior enrichment analyses [116]. A number of DEGs were used for GO analyses in all three GO structures: biological process (BP), molecular function (MF) and cellular component (CC).

\section{Synthesis of CDNA for quantitative PCR}

Reverse transcription was performed using the QuantiTect $^{\odot}$ Reverse Transcription Procedure (Qiagen, Australia). Briefly, $0.5 \mu \mathrm{g}$ of purified total RNA was used per reaction and incubated in gDNA Wipeout Buffer at $42^{\circ} \mathrm{C}$ for $2 \mathrm{~min}$ to eliminate traces of genomic DNA, followed by reverse transcription at the same temperature for $30 \mathrm{~min}$. The cDNA obtained was used as a template in the quantitative PCR (qPCR) analysis and diluted 1:10 prior to use.

\section{Primer design}

Sequencing primers were designed using Primer Express $^{\oplus}$ Software v2.0 (Applied Biosystems, USA). Reference primers used for normalization of qPCR results in the samples of $A$. aspera were adopted from previous studies [15,18,57] and listed in Additional file 14: Table S11. Additional primers were designed from RNA-Seq data for the selected DEGs based on DiffKAP (Additional file 15: Table S12).

For checking the specificity of primers towards coral or algal cDNA, a standard PCR amplification was carried out using aposymbiotic coral cDNA (from the coral $A$. millepora gametes) and coral-algal cDNA mix (from $A$. millepora). PCR conditions were: initial step at $94^{\circ} \mathrm{C}$ for $1 \mathrm{~min} ; 35$ cycles of $94^{\circ} \mathrm{C} 20 \mathrm{~s}, 60^{\circ} \mathrm{C} 20 \mathrm{~s}$ and $72^{\circ} \mathrm{C} 1.5 \mathrm{~min}$; a final extension phase at $72^{\circ} \mathrm{C}$ for $10 \mathrm{~min}$, followed by samples storage at $4^{\circ} \mathrm{C}$.

\section{Quantitative PCR and gene expression analysis}

The quantitative PCR assays were done by an Eppendorf 5075 (Applied Biosystems, USA) robot using SYBR Green PCR master mix (Applied Biosystems, UK) in 384-well plates in a 7900HT Fast Real-time PCR System (Applied Biosystems, USA). PCR conditions were: initial denaturation of $10 \mathrm{~min}$ at $95^{\circ} \mathrm{C}$, followed by 45 cycles of $95^{\circ} \mathrm{C}$ for $15 \mathrm{~s}$ and $60^{\circ} \mathrm{C}$ for $1 \mathrm{~min}$. At the end, a dissociation step was included: $95^{\circ} \mathrm{C}$ for $2 \mathrm{~min}, 60^{\circ} \mathrm{C}$ for $15 \mathrm{~s}$ and $95^{\circ} \mathrm{C}$ for $15 \mathrm{~s}$. The final reaction volume was $10 \mu \mathrm{l}$ and included $300 \mathrm{nM}$ of primers. All reactions were carried out in two technical replicates. The expression 
levels of targeted genes were quantified according to geNorm directions [117]. The relative quantification method was applied for the relative abundance estimation of analysed genes using the best reference genes that showed the most stable expression patterns and specificity for Symbiodinium or coral. Five biological replicates were carried out for each $\mathrm{qPCR}$ and the mean expression level was obtained (ratio of treatment vs. control).

From the initial pool of potential reference genes (Additional file 14: Table S11), we selected the most suitable housekeeping genes (HKG) using GeNorm software (http://medgen.ugent.be/ jvdesomp/genorm/) that showed the most stable expression pattern under the experimental conditions applied in this study. The best HKGs for Symbiodinium used here were Cyclophin (Cyc) and Tubulin (Tub) with $M$ value 0.196 and minimum of two reference genes recommended $(V 2 / 3=0.0749)$. For coral gene expression analyses the best HKGs were ribosomal genes L12 (GenBank ID: EZ024706) and L13 (GenBank ID: EZ040625) with $M$ value 0.284 and again minimum of two reference genes required for accurate normalization under our experimental conditions $(V 2 / 3=0.211)$. The expression of each gene was determined from the $C_{\mathrm{T}}$ (cycles threshold) value that corresponds to the number of cycles required for the PCR amplification to reach a fixed threshold in the exponential phase [118]. A specific threshold of 0.1 was used for obtaining $C_{\mathrm{T}}$ values that were transformed into quantities using maximal PCR efficiency for each gene $(E=2)$. The real-time dissociation curve was used to check for the presence of a unique PCR product. The results of qPCR and $k$-mer (DiffKAP method) analyses are presented on a $\log _{2}$ scale.

\section{Statistical analysis}

Statistical analyses were performed using STATISTICA 7.0 (Statsoft Inc., Tulsa, USA). All data were tested for normality and homogeneity of variance and where assumptions were violated; the data were corrected by transformations. Non-parametric equivalents of tests were used in cases where assumptions were violated despite transformations. A Kruskal-Wallis test was used to determine the effect of time and nutrient, long-term temperature stress on Symbiodinium photosynthetic activity in $A$. aspera, whilst a $t$-test was used to determine the effect of short-term stress.

\section{Availability of supporting data}

This project was submitted to NCBI BioProject with BioProject IDs: PRJNA266455 (http://www.ncbi.nlm.nih. gov/bioproject/?term=PRJNA266455); PRJNA266456 (http://www.ncbi.nlm.nih.gov/bioproject/?term=PRJNA26 6456); PRJNA266457 (http://www.ncbi.nlm.nih.gov/bioproject/?term=PRJNA266457); PRJNA266458 (http:// www.ncbi.nlm.nih.gov/bioproject/?term=PRJNA266458) and PRJNA266459 (http://www.ncbi.nlm.nih.gov/bioproject/?term=PRJNA266459). The raw sequencing reads are deposited in NCBI SRA (Short Read Archive; http://www. ncbi.nlm.nih.gov/sra/) with the following accession numbers: SRX752503 (for C24); SRX752504 (for C72); SRX752505 (for STE); SRX752506 (for LTE) and SRX752 507 (for N).

\section{Additional files}

Additional file 1: Symbiont cells density and chlorophyll a

concentration. Symbiont cells density (A) and chlorophyll a concentration

(B) in the coral A. aspera exposed to thermal and nutrient stress conditions. All data are given as the means from five independent biological replicates \pm SD. Values were considered significantly different if the $P$ value was $<0.05\left(^{*}\right)$.

Additional file 2: Table S1. The DiffKAP run summaries for STE experiment using C24 as a control after $24 \mathrm{~h}$.

Additional file 3: Table S2. The DiffKAP run summaries for LTE experiment using $\mathrm{C} 72$ as a control after $72 \mathrm{~h}$.

Additional file 4: Table S3. The DiffKAP run summaries for nutreint enrichment (N) experiment using C72 as a control after $72 \mathrm{~h}$.

Additional file 5: Table S4. Up-regulated DEGs common in all experimental conditions. Best BLASTx hits correspond to $E$ value equal to and smaller than $10^{-15}$

Additional file 6: Table S5. Down-regulated DEGs common in all experimental conditions. Best BLASTx hits correspond to $E$ value equal to and smaller than $10^{-15}$

Additional file 7: The relative gene expression. The relative expression of coral and algal genes within the coral host $A$. aspera exposed to heat (A) and nutrient stress (B) for a 3-day period using $\mathrm{QPCR}$ and $k$-mer (DiffKAP method) analyses. In $\mathrm{QPCR}$, data normalization of the relative quantities was done using two most stable reference genes (based on the GeNorm analysis) and all data are given as the means of values obtained from five independent biological replicates. From $k$-mer analysis, the fold of change (FoC) for DEGs is calculated from the Ratio of Median (RoM) from a pool of five biological replicates with a cut-off value of 1.5 -fold change (treatment vs. control). Results were presented on $\log _{2}$ scale as Treatment versus CTRL ratio.

Additional file 8: Table S6. Biological processes (BP) that have been induced by thermal (1-day and 3-day) and nutrient stress listing only the top 10 most enriched BP processes.

Additional file 9: Table S7. Molecular functions (MF) enriched by thermal (1-day and 3-day) and nutrient stress listing only the top 10 most enriched MF per treatment.

Additional file 10: Table S8. Cellular component (CC) enriched by thermal (1-day and 3-day) and nutrient stress listing only the top 10 most enriched CC per treatment.

Additional file 11: Table S9. Taxonomic distribution of sequences (reads) from the coral holobiont after a 1-day thermal stress condition was obtained after aligning Illumina short reads to public sequence databases and the Symbiodinium de novo transcriptome assemblies from our group.

Additional file 12: Table S10. Taxonomic distribution of sequences (reads) from the coral holobiont after exposure to the 3-day thermal and nutrient stress conditions was obtained after aligning Illumina short reads to public sequence databases and the Symbiodinium de novo transcriptome assemblies from our group.

Additional file 13: Supporting Information.

Additional file 14: Table S11. Primer sequences, amplicon length and gene accession number of Symbiodinum [57] and coral house-keeping genes [18] used in this study.

Additional file 15: Table S12. Primer sequences, the amplicon length and melting temperature for the primers used in the $\mathrm{GPCR}$ analyses. 
Primers were generated from RNA-Seq data and selected from DEGs based on the DiffKAP method.

\section{Competing interests}

The authors declare that they have no competing interests.

\section{Authors' contributions}

NNR, PK, SD and OHG envisioned this study. NNR and PK performed experimental work. NNR cordinated the work and drafted the manuscript. CKC carried out the bioinformatics analysis. EYSL and DE participated in bioinformatic analyses. All authors participated in writing the manuscript and approved the final verion of the manuscript.

\section{Acknowledgements}

This work was supported by a University of Queensland Postdoctoral Fellowship for Women and a Discovery Early Career Researcher Award (DECRA) by Australian Research Council to NNR, as well as the ARC Centre of Excellence for Coral Reef Studies (www.coralcoe.org.au). The authors would like to acknowledge funding support from the Australian Research Council Project LP0989200

\section{Author details}

${ }^{1}$ School of Biological Sciences, The University of Queensland, Brisbane Qld 4072, Australia. ${ }^{2}$ Australian Institute of Marine Science, Townsville MC, Qld 4810, Australia. ${ }^{3}$ School of Agriculture and Food Sciences, The University of Queensland, Brisbane, Qld 4072, Australia. ${ }^{4}$ University of Queensland Centre for Clinical Research, The University of Queensland, Brisbane, Qld 4029, Australia. ${ }^{5}$ School of Plant Biology, University of Western Australia, Perth, WA, Australia 6. ${ }^{6}$ Australian Centre for Plant Functional Genomics, The University of Queensland, Brisbane, Qld 4072, Australia. ' Global Change Institute and ARC Centre of Excellence for Coral Reef Studies, The University of Queensland, Brisbane, Qld 4072, Australia.

Received: 5 January 2014 Accepted: 12 November 2014

Published: 2 December 2014

\section{References}

1. Muscatine L, Pool RR, Trench RK: Symbiosis of algae and invertebrates: aspects of the symbiont surface and the host-symbiont interface. Trans Am Microsc Soc 1975, 94(4):450-469.

2. Yellowlees D, Rees TA, Leggat W: Metabolic interactions between algal symbionts and invertebrate hosts. Plant Cell Environ 2008, 31(5):679-694.

3. Venn AA, Loram JE, Douglas AE: Photosynthetic symbioses in animals. J Exp Bot 2008, 59(5):1069-1080.

4. Hoegh-Guldberg $\mathrm{O}$ : Climate change, coral bleaching and the future of the world's coral reefs. Mar Freshw Res 1999, 50(8):839-866.

5. Berkelmans R: Time-integrated thermal bleaching thresholds of reefs and their variation on the Great Barrier Reef. Mar Ecol Prog Ser 2002, 229:73-82.

6. Hoegh-Guldberg O, Mumby PJ, Hooten AJ, Steneck RS, Greenfield P, Gomez E, Harvell CD, Sale PF, Edwards AJ, Caldeira K, Knowlton N, Eakin CM, Iglesias-Prieto R, Muthiga N, Bradbury RH, Dubi A, Hatziolos ME: Coral reefs under rapid climate change and ocean acidification. Science 2007, 318(5857):1737-1742.

7. Carpenter SR, Caraco NF, Correll DL, Howarth RW, Sharpley AN, Smith VH: Nonpoint pollution of surface waters with phosphorus and nitrogen. Ecol Appl 1998, 8(3):559-568.

8. Koop K, Booth D, Broadbent A, Brodie J, Bucher D, Capone D, Coll J, Dennison W, Erdmann M, Harrison P, Hoegh-Guldberg O, Hutchings P Jones GB, Larkum AWD, O'Neil J, Steven A, Tentori E, Ward S, Williamson J, Yellowlees D: ENCORE: The effect of nutrient enrichment on coral reefs. Synthesis of results and conclusions. Mar Pollut Bull 2001, 42(2):91-120.

9. Szmant AM: Nutrient enrichment on coral reefs: Is it a major cause of coral reef decline? Estuar Coast Shelf Sci 2002, 25(4 B):743-766.

10. Wiedenmann J, D/'Angelo C, Smith EG, Hunt AN, Legiret F-E, Postle AD, Achterberg EP: Nutrient enrichment can increase the susceptibility of reef corals to bleaching. Nature Clim Change 2012. advance online publication.

11. Meyer JL, Schultz ET: Tissue condition and growth rate of corals associated with schooling fish. Limnol Oceanogr 1985, 30(1):157-166.

12. Marubini F, Davies PS: Nitrate increases zooxanthellae population density and reduces skeletogenesis in corals. Mar Biol 1996, 127(2):319-328.
13. Stimson J: The temporal pattern and rate of release of zooxanthellae from the reef coral Pocillopora damicornis (Linnaeus) under nitrogen-enrichment and control conditions. J Exp Mar Bio Ecol 1991, 153(1):63-74.

14. Kaniewska P, Campbell PR, Kline DI, Rodriguez-Lanetty M, Miller DJ, Dove S, Hoegh-Guldberg O: Major cellular and physiological impacts of ocean acidification on a reef building coral. PLoS One 2012, 7(4):e34659.

15. Rosic NN, Pernice M, Dove S, Dunn S, Hoegh-Guldberg O: Gene expression profiles of cytosolic heat shock proteins $\mathrm{Hsp} 70$ and Hsp90 from symbiotic dinoflagellates in response to thermal stress: possible implications for coral bleaching. Cell Stress Chaperones 2011, 16(1):69-80.

16. Rosic NN, Pernice M, Dunn S, Dove S, Hoegh-Guldberg O: Differential regulation by heat stress of novel cytochrome P450 genes from the dinoflagellate symbionts of reef-building corals. Appl Environ Microbiol 2010, 76(9):2823-2829.

17. Rodriguez-Lanetty M, Harii S, Hoegh-Guldberg O: Early molecular responses of coral larvae to hyperthermal stress. Mol Ecol 2009, 18(24):5101-5114

18. Pernice M, Dunn SR, Miard T, Dufour S, Dove S, Hoegh-Guldberg O: Regulation of apoptotic mediators reveals dynamic responses to thermal stress in the reef building coral Acropora millepora. PLoS One 2011, 6(1):e16095.

19. Pernice M, Meibom A, Van Den Heuvel A, Kopp C, Domart-Coulon I, Hoegh-Guldberg O, Dove S: A single-cell view of ammonium assimilation in coral-dinoflagellate symbiosis. ISME J 2012, 6(7):1314-1324.

20. Vega Thurber RL, Barott KL, Hall D, Liu H, Rodriguez-Mueller B, Desnues C, Edwards RA, Haynes M, Angly FE, Wegley L, Rohwer FL: Metagenomic analysis indicates that stressors induce production of herpes-like viruses in the coral Porites compressa. Proc Natl Acad Sci U S A 2008, 105(47):18413-18418.

21. Leggat W, Seneca F, Wasmund K, Ukani L, Yellowlees D, Ainsworth TD: Differential responses of the coral host and their algal symbiont to thermal stress. PLoS One 2011, 6(10):e26687.

22. Moya A, Huisman L, Ball EE, Hayward DC, Grasso LC, Chua CM, Woo HN, Gattuso JP, Forêt S, Miller DJ: Whole Transcriptome Analysis of the Coral Acropora millepora Reveals Complex Responses to CO 2-driven Acidification during the Initiation of Calcification. Mol Ecol 2012, 21(10):2440-2454.

23. Sunagawa S, Wilson EC, Thaler M, Smith ML, Caruso C, Pringle JR, Weis VM, Medina M, Schwarz JA: Generation and analysis of transcriptomic resources for a model system on the rise: The sea anemone Aiptasia pallida and its dinoflagellate endosymbiont. BMC Genomics 2009, 10:258.

24. Moya A, Ganot P, Furla P, Sabourault C: The transcriptomic response to thermal stress is immediate, transient and potentiated by ultraviolet radiation in the sea anemone Anemonia viridis. Mol Ecol 2012, 21(5):1158-1174.

25. Voolstra CR, Sunagawa S, Schwarz JA, Coffroth MA, Yellowlees D, Leggat W, Medina M: Evolutionary analysis of orthologous CDNA sequences from cultured and symbiotic dinoflagellate symbionts of reef-building corals (Dinophyceae: Symbiodinium). Comp Biochem Physiol Part D Genomics Proteomics 2009, 4(2):67-74

26. DeSalvo MK, Sunagawa S, Fisher PL, Voolstra CR, Iglesias-Prieto R, Medina M: Coral host transcriptomic states are correlated with Symbiodinium genotypes. Mol Ecol 2010, 19(6):1174-1186.

27. Morozova O, Marra MA: Applications of next-generation sequencing technologies in functional genomics. Genomics 2008, 92(5):255-264.

28. Meyer E, Aglyamova GV, Matz MV: Profiling gene expression responses of coral larvae (Acropora millepora) to elevated temperature and settlement inducers using a novel RNA-Seq procedure. Mol Ecol 2011, 20(17):3599-3616.

29. Barshis DJ, Ladner JT, Oliver TA, Seneca FO, Traylor-Knowles N, Palumbi SR: Genomic basis for coral resilience to climate change. Proc Natl Acad Sci U S A 2013, 110(4):1387-1392.

30. Kenkel CD, Meyer E, Matz MV: Gene expression under chronic heat stress in populations of the mustard hill coral (Porites astreoides) from different thermal environments. Mol Ecol 2013, 22(16):4322-4334.

31. Dubinsky Z, Stambler N, Ben-Zion M, McCloskey LR, Muscatine L, Falkowski PG: The effect of external nutrient resources on the optical properties and photosynthetic efficiency of Stylophora pistillata. Proc R Soc: Biol Sci 1990, 239(1295):231-246.

32. McClanahan TR: The relationship between bleaching and mortality of common corals. Mar Biol 2004, 144(6):1239-1245.

33. Rosic N, Ling EY, Chan CK, Lee HC, Kaniewska P, Edwards D, Dove S, Hoegh-Guldberg O: Unfolding the secrets of coral-algal symbiosis. ISME 2014 doi:10.1038/ismej.2014.182.

34. Berkelmans R, Willis BL: Seasonal and local spatial patterns in the upper thermal limits of corals on the inshore Central Great Barrier Reef. Coral Reefs 1999, 18(3):219-228. 
35. Howells EJ, Beltran VH, Larsen NW, Bay LK, Willis BL, Van Oppen MJH: Coral thermal tolerance shaped by local adaptation of photosymbionts. Nat Climate Change 2012, 2(2):116-120.

36. Middlebrook R, Hoegh-Guldberg O, Leggat W: The effect of therma history on the susceptibility of reef-building corals to thermal stress. J Exp Biol 2008, 211(Pt 7):1050-1056.

37. Jokiel PL: Temperature stress and coral bleaching. In Coral Health and Disease. Edited by Rosenberg E, Loya Y. New York: Springer; 2004:401-425.

38. Fitt WK, Brown BE, Warner ME, Dunne RP: Coral bleaching: Interpretation of thermal tolerance limits and thermal thresholds in tropical corals. Coral Reefs 2001, 20(1):51-65.

39. Berkelmans R, van Oppen MJ: The role of zooxanthellae in the thermal tolerance of corals: a 'nugget of hope' for coral reefs in an era of climate change. Proc Biol Sci 2006, 273(1599):2305-2312.

40. Fisher PL, Malme MK, Dove S: The effect of temperature stress on coral-Symbiodinium associations containing distinct symbiont types. Coral Reefs 2012, 31(2):473-485.

41. Fitt WK, Gates RD, Hoegh-Guldberg O, Bythell JC, Jatkar A, Grottoli AG, Gomez M, Fisher P, Lajuenesse TC, Pantos O, Iglesias-Prieto R, Franklin DJ, Rodrigues LJ, Torregiani JM, van Woesik R, Lesser MP: Response of two species of Indo-Pacific corals, Porites cylindrica and Stylophora pistillata, to short-term thermal stress: The host does matter in determining the tolerance of corals to bleaching. J Exp Marine Biol Ecol 2009, 373(2):102-110.

42. Rowan R: Coral bleaching: thermal adaptation in reef coral symbionts. Nature 2004, 430(7001):742

43. Abrego D, Ulstrup KE, Willis BL, van Oppen MJ: Species-specific interactions between algal endosymbionts and coral hosts define their bleaching response to heat and light stress. Proc Bio/ Sci 2008, 275(1648):2273-2282.

44. Tchernov D, Gorbunov MY, de Vargas C, Narayan Yadav S, Milligan AJ, Haggblom M, Falkowski PG: Membrane lipids of symbiotic algae are diagnostic of sensitivity to thermal bleaching in corals. Proc Natl Acad Sci U S A 2004, 101(37):13531-13535.

45. Hoegh-Guldberg O, Smith GJ: The effect of sudden changes in temperature, light and salinity on the population density and export of zooxanthellae from the reef corals Stylophora pistillata Esper and Seriatopora hystrix Dana. J Exp Marine Biol Ecol 1989, 129(3):279-303.

46. Wang Z, Gerstein M, Snyder M: RNA-Seq: a revolutionary tool for transcriptomics. Nat Rev Genet 2009, 10(1):57-63.

47. Coles SL, Jokiel PL: Effects of temperature on photosynthesis and respiration in hermatypic corals. Mar Biol 1977, 43(3):209-216.

48. Lesser MP, Farrell JH: Exposure to solar radiation increases damage to both host tissues and algal symbionts of corals during thermal stress. Coral Reefs 2004, 23(3):367-377.

49. Takahashi S, Murata N: How do environmental stresses accelerate photoinhibition? Trends Plant Sci 2008, 13(4):178-182.

50. Hill R, Larkum AW, Frankart C, Kuhl M, Ralph PJ: Loss of Functional Photosystem II Reaction Centres in Zooxanthellae of Corals Exposed to Bleaching Conditions: Using Fluorescence Rise Kinetics. Photosynth Res 2004, 82(1):59-72.

51. Warner ME, Fitt WK, Schmidt GW: Damage to photosystem II in symbiotic dinoflagellates: a determinant of coral bleaching. Proc Natl Acad Sci U S A 1999, 96(14):8007-8012.

52. Takahashi S, Badger MR: Photoprotection in plants: a new light on photosystem II damage. Trends Plant Sci 2011, 16(1):53-60.

53. McGinley MP, Aschaffenburg MD, Pettay DT, Smith RT, LaJeunesse TC, Warner ME: Transcriptional response of two core photosystem genes in Symbiodinium spp. exposed to thermal stress. PLoS One 2012, 7(12):e50439.

54. Wang $Y$, Morse D: Rampant polyuridylylation of plastid gene transcripts in the dinoflagellate Lingulodinium. Nucleic Acids Res 2006, 34(2):613-619.

55. Lange H, Sement FM, Canaday J, Gagliardi D: Polyadenylation-assisted RNA degradation processes in plants. Trends Plant Sci 2009, 14(9):497-504

56. Morey JS, Monroe EA, Kinney AL, Beal M, Johnson JG, Hitchcock GL, Van Dolah FM: Transcriptomic response of the red tide dinoflagellate, Karenia brevis, to nitrogen and phosphorus depletion and addition. BMC Genomics 2011, 12:346.

57. Rosic NN, Pernice M, Rodriguez-Lanetty M, Hoegh-Guldberg O: Validation of housekeeping genes for gene expression studies in Symbiodinium exposed to thermal and light stress. Mar Biotechnol (NY) 2011, 13(3):355-365.

58. Ogawa D, Bobeszko T, Ainsworth T, Leggat W: The combined effects of temperature and $\mathrm{CO} 2$ lead to altered gene expression in Acropora aspera. Coral Reefs 2013, 32(4):895-907.
59. Rosic NN, Leggat W, Kaniewska P, Dove S, Hoegh-Guldberg O: New-old hemoglobin-like proteins of symbiotic dinoflagellates. Ecol Evol 2013, 3(4):822-834.

60. Sorek M, Levy O: Influence of the quantity and quality of light on photosynthetic periodicity in coral endosymbiotic Algae. PLoS One 2012, 7(8):e43264.

61. Levy O, Kaniewska P, Alon S, Eisenberg E, Karako-Lampert S, Bay LK, Reef R, Rodriguez-Lanetty M, Miller DJ, Hoegh-Guldberg O: Complex diel cycles of gene expression in coral-algal symbiosis. Science 2011, 331(6014):175.

62. Bellantuono AJ, Granados-Cifuentes C, Miller DJ, Hoegh-Guldberg O, Rodriguez-Lanetty M: Coral Thermal Tolerance: Tuning Gene Expression to Resist Thermal Stress. PLoS One 2012, 7(11):e50685.

63. Mayfield AB, Wang LH, Tang PC, Fan TY, Hsiao YY, Tsai CL, Chen CS: Assessing the impacts of experimentally elevated temperature on the biological composition and molecular chaperone gene expression of a reef coral. PLoS One 2011, 6(10):e26529.

64. Lin S: Genomic understanding of dinoflagellates. Res Microbio/ 2011, 162(6):551-569.

65. Bay LK, Ulstrup KE, Nielsen HB, Jarmer H, Goffard N, Willis BL, Miller DJ, Van Oppen $\mathrm{MJH}$ : Microarray analysis reveals transcriptional plasticity in the reef building coral Acropora millepora. Mol Ecol 2009, 18(14):3062-3075.

66. Smith-Keune C, Dove S: Gene expression of a green fluorescent protein homolog as a host-specific biomarker of heat stress within a reef-building coral. Marine Biotechnol 2008, 10(2):166-180.

67. Kenkel CD, Sheridan C, Leal MC, Bhagooli R, Castillo KD, Kurata N, McGinty E, Goulet TL, Matz MV: Diagnostic gene expression biomarkers of coral thermal stress. Mol Ecol Resour 2014, 14(4):667-678.

68. Roth MS, Deheyn DD: Effects of cold stress and heat stress on coral fluorescence in reef-building corals. Sci Rep 2013, 3:1421.

69. Ciechanover A, Orian A, Schwartz AL: Ubiquitin-mediated proteolysis: Biological regulation via destruction. Bioessays 2000, 22(5):442-451

70. Deisenroth C, Zhang Y: The Ribosomal Protein-Mdm2-p53 Pathway and Energy Metabolism: Bridging the Gap between Feast and Famine. Genes Cancer 2011, 2(4):392-403.

71. Xirodimas DP, Sundqvist A, Nakamura A, Shen L, Botting C, Hay RT: Ribosomal proteins are targets for the NEDD8 pathway. EMBO Rep 2008, 9(3):280-286

72. Li Z, Lee I, Moradi E, Hung NJ, Johnson AW, Marcotte EM: Rational extension of the ribosome biogenesis pathway using network-guided genetics. PLoS Biol 2009, 7(10):e1000213

73. Burger AM, Seth AK: The ubiquitin-mediated protein degradation pathway in cancer: Therapeutic implications. Eur J Cancer 2004, 40(15):2217-2229.

74. Voolstra CR, Schnetzer J, Peshkin L, Randall CJ, Szmant AM, Medina M: Effects of temperature on gene expression in embryos of the coral Montastraea faveolata. BMC Genomics 2009, 10:627.

75. Huang SP, Lin KL, Fang LS: The involvement of calcium in heat-induced coral bleaching. Zoological Studies 1998, 37(2):89-94.

76. Mailloux RJ, Beriault R, Lemire J, Singh R, Chenier DR, Hamel RD, Appanna VD: The tricarboxylic acid cycle, an ancient metabolic network with a novel twist. PLoS One 2007, 2(8):e690.

77. Fernandez AM, Torres-Alemán I: The many faces of insulin-like peptide signalling in the brain. Nat Rev Neurosci 2012, 13(4):225-239.

78. Anctil M: Chemical transmission in the sea anemone Nematostella vectensis: A genomic perspective. Comp Biochem Physiol Part D Genomics Proteomics 2009, 4(4):268-289.

79. Loya $Y$, Lubinevsky H, Rosenfeld M, Kramarsky-Winter E: Nutrient enrichment caused by in situ fish farms at Eilat, Red Sea is detrimental to coral reproduction. Mar Pollut Bull 2004, 49(4):344-353.

80. Bassim KM, Sammarco PW: Effects of temperature and ammonium on larval development and survivorship in a scleractinian coral (Diploria strigosa). Mar Biol 2003, 142(2):241-252.

81. Hoogenboom MO, Campbell DA, Beraud E, Dezeeuw K, Ferrier-Pages C: Effects of light, food availability and temperature stress on the function of photosystem II and photosystem I of coral symbionts. PLoS One 2012, 7(1):e30167.

82. Lesser MP: Oxidative stress in marine environments: biochemistry and physiological ecology. Annu Rev Physiol 2006, 68:253-278.

83. Lesser MP: Oxidative stress causes coral bleaching during exposure to elevated temperatures. Coral Reefs 1997, 16(3):187-192.

84. Bayer T, Aranda M, Sunagawa S, Yum LK, Desalvo MK, Lindquist E, Coffroth MA, Voolstra CR, Medina M: Symbiodinium transcriptomes: genome 
insights into the dinoflagellate symbionts of reef-building corals. PLOS One 2012, 7(4):e35269.

85. Desalvo MK, Voolstra CR, Sunagawa S, Schwarz JA, Stillman JH, Coffroth MA, Szmant AM, Medina M: Differential gene expression during thermal stress and bleaching in the Caribbean coral Montastraea faveolata. Mol Ecol 2008, 17(17):3952-3971.

86. Richier S, Merle PL, Furla P, Pigozzi D, Sola F, Allemand D: Characterization of superoxide dismutases in anoxia- and hyperoxia-tolerant symbiotic cnidarians. Biochimica et Biophysica Acta - General Subjects 2003, 1621(1):84-91.

87. Császár NBM, Seneca FO, Van Oppen MJH: Variation in antioxidant gene expression in the scleractinian coral Acropora millepora under laboratory thermal stress. Mar Ecol Prog Ser 2009, 392:93-102.

88. Bosch TCG, McFall-Ngai MJ: Metaorganisms as the new frontier. Zoology 2011, 114(4):185-190.

89. Knowlton N, Rohwer F: Multispecies microbial mutualisms on coral reefs: the host as a habitat. Am Nat 2003, 162(4 Suppl):S51-62

90. Meyer E, Aglyamova GV, Wang S, Buchanan-Carter J, Abrego D, Colbourne $\mathrm{JK}$, Willis BL, Matz MV: Sequencing and de novo analysis of a coral larval transcriptome using 454 GSFIx. BMC Genomics 2009, 10:219.

91. Novaes E, Drost DR, Farmerie WG, Pappas GJ Jr, Grattapaglia D, Sederoff RR, Kirst M: High-throughput gene and SNP discovery in Eucalyptus grandis, an uncharacterized genome. BMC Genomics 2008, 9:312

92. Bourne DG, Garren M, Work TM, Rosenberg E, Smith GW, Harvell CD: Microbial disease and the coral holobiont. Trends Microbiol 2009, 17(12):554-562.

93. Littman R, Willis BL, Bourne DG: Metagenomic analysis of the coral holobiont during a natural bleaching event on the Great Barrier Reef. Environ Microbiol Rep 2011, 3(6):651-660

94. Weston AJ, Dunlap WC, Shick JM, Klueter A, Iglic K, Vukelic A, Starcevic A, Ward M, Wells ML, Trick CG, Long PF: A profile of an endosymbiont-enriched fraction of the coral Stylophora pistillata reveals proteins relevant to microbial-host interactions. Mol Cell Proteomics 2012, 11(6): doi:10.1074/mcp. M111.015487.

95. Weis VM, Davy SK, Hoegh-Guldberg O, Rodriguez-Lanetty M, Pringle JR: Cell biology in model systems as the key to understanding corals. Trends Ecol Evol 2008, 23(7):369-376.

96. LaJeunesse TC, Loh WKW, Van Woesik R, Hoegh-Guldberg O, Schmidt GW, Fitt WK: Low symbiont diversity in southern Great Barrier Reef corals, relative to those of the Caribbean. Limnol Oceanogr 2003, 48(5):2046-2054.

97. Dove S: Scleractinian corals with photoprotective host pigments are hypersensitive to thermal bleaching. Mar Ecol Prog Ser 2004, 272:99-116.

98. Iglesias-Prieto R, Matta JL, Robins WA, Trench RK: Photosynthetic response to elevated temperature in the symbiotic dinoflagellate Symbiodinium microadriaticum in culture. Proc Natl Acad Sci U S A 1992, 89(21):10302-10305.

99. Potts DC, Swart PK: Water temperature as an indicator of environmental variability on a coral reef. Limnology Oceanogr 1984, 29(3):504-516.

100. Grover R, Maguer JF, Reynaud-Vaganay S, Ferrier-Pages C: Uptake of ammonium by the scleractinian coral Stylophora pistillata: Effect of feeding, light, and ammonium concentrations. Limnol Oceanogr 2002, 47(3):782-790

101. Iglesias-Prieto R, Beltran VH, LaJeunesse TC, Reyes-Bonilla H, Thome PE: Different algal symbionts explain the vertical distribution of dominant reef corals in the eastern Pacific. Proc Biol Sci 2004, 271(1549):1757-1763.

102. Robinson MD, McCarthy DJ, Smyth GK: edgeR: a Bioconductor package for differential expression analysis of digital gene expression data. Bioinformatics 2010, 26(1):139-140.

103. Wang L, Feng Z, Wang X, Wang X, Zhang X: DEGseq: an R package for identifying differentially expressed genes from RNA-seq data. Bioinformatics 2010, 26(1):136-138.

104. Trapnell C, Roberts A, Goff L, Pertea G, Kim D, Kelley DR, Pimentel H, Salzberg SL, Rinn JL, Pachter L: Differential gene and transcript expression analysis of RNA-Seq experiments with TopHat and Cufflinks. Nat Protoc 2012, 7(3):562-578

105. Martin JA, Wang Z: Next-generation transcriptome assembly. Nat Rev Genet 2011, 12(10):671-682

106. Nordstrom KJV, Albani MC, James GV, Gutjahr C, Hartwig B, Turck F, Paszkowski U, Coupland G, Schneeberger K: Mutation identification by direct comparison of whole-genome sequencing data from mutant and wild-type individuals using k-mers. Nat Biotechnol 2013,. advance online publication.
107. Reichman JR, Wilcox TP, Vize PD: PCP Gene Family in Symbiodinium from Hippopus hippopus: Low Levels of Concerted Evolution, Isoform Diversity, and Spectral Tuning of Chromophores. Mol Biol Evol 2003, 20(12):2143-2154.

108. Marçais G, Kingsford C: A fast, lock-free approach for efficient parallel counting of occurrences of k-mers. Bioinformatics 2011, 27(6):764-770.

109. Kurtz S, Narechania A, Stein J, Ware D: A new method to compute k-mer frequencies and its application to annotate large repetitive plant genomes. BMC Genomics 2008, 9(1):517.

110. Boutet E, Lieberherr D, Tognolli M, Schneider M, Bairoch A: UniProtKB/ Swiss-Prot. Methods Mol Biol 2007, 406 (Journal Article):89.

111. da Huang W, Sherman BT, Lempicki RA: Systematic and integrative analysis of large gene lists using DAVID bioinformatics resources. Nat Protoc 2009, 4(1):44-57.

112. da Huang W, Sherman BT, Lempicki RA: Bioinformatics enrichment tools: paths toward the comprehensive functional analysis of large gene lists. Nucleic Acids Res 2009, 37(1):1-13.

113. Hochberg Y, Benjamini Y: More powerful procedures for multiple significance testing. Stat Med 1990, 9(7):811-818.

114. Haack TB, Hogarth P, Kruer MC, Gregory A, Wieland T, Schwarzmayr T, Graf E, Sanford L, Meyer E, Kara E, Cuno SM, Harik SI, Dandu VH, Nardocci N, Zorzi G, Dunaway T, Tarnopolsky M, Skinner S, Frucht S, Hanspal E, Schrander-Stumpel C, Heron D, Mignot C, Garavaglia B, Bhatia K, Hardy J, Strom TM, Boddaert N, Houlden HH, Kurian MA, et al: Exome sequencing reveals de novo WDR45 mutations causing a phenotypically distinct, X-linked dominant form of NBIA. Am J Hum Genet 2012, 91(6):1144-1149.

115. Dennis G Jr, Sherman BT, Hosack DA, Yang J, Gao W, Lane HC, Lempicki RA: DAVID: Database for Annotation, Visualization, and Integrated Discovery. Genome Biol 2003, 4(5):3.

116. Jantzen SG, Sutherland BJ, Minkley DR, Koop BF: GO Trimming: Systematically reducing redundancy in large Gene Ontology datasets. BMC Res Notes 2011, 4:267.

117. Vandesompele J, De Preter K, Pattyn F, Poppe B, Van Roy N, De Paepe A, Speleman F: Accurate normalization of real-time quantitative RT-PCR data by geometric averaging of multiple internal control genes. Genome Biol 2002, 3(7). RESEARCH0034.

118. Walker NJ: A technique whose time has come. Science 2002, 296(5567):557-559.

\section{doi:10.1186/1471-2164-15-1052}

Cite this article as: Rosic et al:: Early transcriptional changes in the reef-building coral Acropora aspera in response to thermal and nutrient stress. BMC Genomics 2014 15:1052.

\section{Submit your next manuscript to BioMed Central and take full advantage of:}

- Convenient online submission

- Thorough peer review

- No space constraints or color figure charges

- Immediate publication on acceptance

- Inclusion in PubMed, CAS, Scopus and Google Scholar

- Research which is freely available for redistribution 